\title{
A new large-scale suspended sediment model and its application over the United States
}

Hong-Yi Li ${ }^{*}$, Zeli Tan ${ }^{2}$, Hongbo $\mathrm{Ma}^{3}$, Zhenduo Zhu ${ }^{4}$, Guta Wakbulcho Abeshu ${ }^{1}$, Senlin Zhu ${ }^{1,5}$, Sagy 5

Cohen ${ }^{6}$, Tian $\mathrm{Zhou}^{2}$, Donghui $\mathrm{Xu}^{2}$, and L. Ruby Leung ${ }^{2}$

${ }^{1}$ Department of Civil and Environmental Engineering, University of Houston, Houston, Texas, USA

${ }^{2}$ Pacific Northwest National Laboratory, Richland, Washington, USA

${ }^{3}$ Department of Civil and Environmental Engineering, University of California Irvine, Irvine, California, USA

${ }^{4}$ Department of Civil, Structural and Environmental Engineering, University at Buffalo, The State University of New York,

10 Buffalo, New York, USA

${ }^{5}$ Currently at Yangzhou University, Yangzhou, China

${ }^{6}$ Department of Geography, University of Alabama, Tuscaloosa, Alabama, USA

*Correspondence to: Hong-Yi Li (hongyili.jadison@gmail.com) 
25 Abstract. Suspended sediment plays a vital role in the regional and global cycling of carbon and nutrients by carrying carbon and nutrients from headwaters into lowland rivers and the oceans. Sediment transport through river systems is often fundamentally modified by human activities like reservoir management. However, a physically based representation of sediment transport is still missing in most existing earth system models (ESMs), which are essential tools for modeling and predicting earth system changes. Here, we introduce a multi-process river sediment module for ESMs, which includes: 1) hillslope soil erosion and sediment discharge into streams; 2) sediment transport processes through river networks; 3) reservoir operation based on the inflows from upstream areas and water demand from downstream areas; and 4) sediment trapping by reservoirs. All model parameters are estimated a priori without calibration. We apply this new sediment modeling framework to the contiguous United States and validate it against historical observations of monthly streamflow and sediment discharges at 35 river gauges. The model reasonably well captures the long-term balance and seasonal variations of suspended sediment

35 in large river systems. Furthermore, our model results show that suspended sediment discharge in managed rivers is affected more by reservoirs' direct trapping of sediment particles than by their flow regulation. This new sediment module enables future modeling of the transportation and transformation of carbon and nutrients carried by the fine sediment along the riverocean continuum to close the global carbon and nutrients cycles. 


\section{Introduction}

Fluvial suspended sediment (referred to as suspended sediment) is fine-grained particles that may be diffused throughout the vertical column of rivers via turbulence and transported along rivers (Garcia (Ed.), 2008). It typically consists of fine sand, silt, and clay, which can absorb carbon and nutrients. Recently, increasing evidence showed that suspended sediment transport plays a vital role in regional and global carbon and nutrient cycling (Berhe et al., 2018; Lal, 2003, 2004; Ludwig \& Probst, 1996; Maavara et al., 2020; Van Oost et al., 2007) by carrying carbon and nutrients from soil storage pools into rivers and eventually oceans or lakes. For instance, suspended sediment is a major source of carbon and nutrients sustaining coastal wetlands and deltas (Kirwan \& Megonigal, 2013; Nienhuis et al., 2020). While understanding the global carbon and nutrient cycling has been one of the primary goals of Earth System Models (ESMs), few ESMs have incorporated the representation

65 of suspended sediment and the associated carbon and nutrient fluxes, e.g., particulate organic and inorganic carbon, nitrogen, and phosphorous.

In the field of Earth system modeling, there are two primary reasons for the lack of suspended sediment in current ESMs. First, most ESMs have been developed with a conventional assumption that the lateral carbon fluxes through the land-riverocean continuum are not significant, compared to the carbon dynamics within the larger carbon pool in the atmosphere, land,

70 and ocean or to the vertical carbon fluxes between the atmosphere and the underlying land and ocean. This assumption has now been refuted by data-based empirical studies (Berhe et al., 2018; Lal, 2003, 2004; Ludwig \& Probst, 1996; Maavara et al., 2020; Van Oost et al., 2007). Second, process-based representations of hydrological fluxes, such as overland flow generation and routing, channel routing, and reservoir operations that drive the suspended sediment fluxes, are not included in many ESMs. The recent development of a physically-based large-scale surface flow routing model, Model for Scale Adaptive

75 River Transport (MOSART) (Li et al., 2013; Li, Leung, Getirana, et al., 2015; Li, Leung, Tesfa, et al., 2015; Voisin, Li, et al., 2013; Voisin, Liu, et al., 2013) is one of the few attempts to overcome this obstacle. MOSART explicitly incorporates the processes of overland flow routing across hillslopes, channel routing through tributaries and main channel networks, and water management such as reservoir regulation and surface water withdrawal, thus providing a solid physical basis to represent suspended sediment dynamics in both natural and managed rivers. Therefore, building on the MOSART framework, our first 80 objective is to advance Earth system modeling by introducing a new suspended sediment module in ESMs.

In the field of sediment modeling, there have been several large-scale models of suspended sediment accounting for the spatiotemporal heterogeneity in sediment supply and transport processes (Czuba et al., 2017; Ferguson et al., 2015; Patil et al., 2012; Pelletier, 2012; Schmitt et al., 2016, 2018; Tsuruta et al., 2018; White et al., 2014). However, few have been designed for regional or global applications with explicit accounting for the effects of reservoirs prevalent in most river systems (Nilsson

85 et al., 2005). Among the exceptions are BQART (Syvitski et al., 2003, 2005) and WBMsed (Cohen et al., 2013, 2014; Moragoda \& Cohen, 2020). In BQART, a multivariable regression relationship has been established for each basin between the long-term suspended sediment load (hereafter, "load" refers to sediment discharge/flux) at the basin outlet and several parameters accounting for the average climate, lithology, and anthropogenic conditions at the basin scale (Syvitski et al., 2003, 
2005). WBMsed is a grid-based implementation of BQART running at the daily time step. In WBMsed, each grid is assumed to be the outlet of its upstream drainage area. A BQART-type regression relationship is used to simulate long-term suspended sediment load from the upstream drainage area to the downstream through the grid. A stochastic model is then used to resolve suspended sediment discharge at daily timescale from the long-term suspended sediment discharge (Cohen et al., 2013, 2014).

Despite the pioneering work in developing BQART and WBMsed, these models are not ready to be incorporated into ESMs as their soil erosion and riverine sediment processes are lumped rather than separately represented. Moreover, the inherent empiricism of BQART/WBMsed limits its scalability (from large to small rivers) and, in its current formulation, the models do not explicitly account for erosion processes on the landscape and within the channel systems. This empiricism is thus a hurdle to studying the individual impacts of the first-order processes and their driving factors such as the various human activities like land and water management. Moreover, although WBMsed includes a temporally and spatiality explicit sediment trapping algorithm, it does not explicitly simulate sediment movement from grid-cell to grid-cell. Compared to more physically-based models, this limitation will likely constrain its capabilities in sediment prediction in a changing environment. Hence our second objective is to advance large-scale sediment modeling by designing a physically-based, flexible modeling framework that allows for explicit and separate representation of the first-order processes and their driving factors.

To achieve the two objectives, we propose a new process-based suspended sediment module within MOSART, denoted as MOSART-sediment hereafter. MOSART-sediment consists of 1) hillslope soil erosion and sediment discharge into streams; 2) sediment transport processes through river networks; 3) reservoir effects on riverine sediment fluxes. MOSART has been adopted as the riverine component of the Energy Exascale Earth System Model (E3SM) (Caldwell et al., 2019; Golaz et al., 2019) and the Community Earth System Model (CESM) (Lawrence et al., 2019). MOSART-sediment is thus, by design, part of the earth system modeling framework for applications at the regional or global scales. Importantly, MOSART-sediment is designed to only capture the first-order suspended sediment processes for two reasons: 1) to be consistent and compatible with the complexity, resolution, and computational requirement of regional or global ESMs, parsimonious parameterizations are more desirable. 2) Sediment-relevant data at the regional or larger scales has limited availability compared to those supporting reach-scale or watershed-scale modeling studies (Abeshu et al., 2021), hence prohibiting extensive parameter calibration that is often needed in modeling complex processes and their interactions.

The MOSART-sediment development and testing reported in this study are conducted within E3SM. However,

115 MOSART-sediment is designed in a modular fashion so it can be easily implemented in other ESMs. The rest of this paper is organized as follows. Section 2 introduces the details of MOSART-sediment. Section 3 describes the model application, validation, and additional analysis over the contiguous United States. Section 4 summarizes the conclusions and discusses the limitations and future directions.

\section{Modeling Framework}

120 As shown in Figure 1, MOSART-sediment is developed on top of the water module of MOSART (denoted as MOSARTwater). Here we provide a detailed description of MOSART-sediment, but only a summary description of MOSART-water for 
completeness since more details of the latter can be found in our previous publications (Li et al., 2013; Li, Leung, Getirana, et al., 2015; Li, Leung, Tesfa, et al., 2015; Voisin, Li, et al., 2013; Voisin, Liu, et al., 2013).

\subsection{MOSART-water}

MOSART-water is a spatially distributed model which takes surface and subsurface runoff time series generated from a land model as inputs and performs runoff routing across hillslopes (overland flow routing) and through channels (channel routing) (Li et al., 2013). The fundamental spatial units of MOSART-water can be regular latitude/longitude grid cells or watersheds, and the former is used in this study. Within each spatial unit, surface runoff is first routed across hillslopes and then discharged along with subsurface runoff into a "tributary sub-network" channel before entering the main channel. The

130 spatial units are thus linked via routing through the main channel network, which is constructed in a scale-consistent way across different spatial resolutions based on the hierarchical river tracing method (H. Wu et al., 2011, 2012). The overland flow routing is modeled using the kinematic wave method, while the channel routing can be simulated using either the kinematic wave method or the diffusion wave method. All model parameters are physically based and available globally as described in our previous studies (Li et al., 2013; Li, Leung, Getirana, et al., 2015; Li, Leung, Tesfa, et al., 2015). In these applications of MOSART-water at the regional to global scales, no parameter calibration was conducted.

MOSART-water includes a water management module applied at regional and continental scales (Li, Leung, Tesfa, et al., 2015; Voisin, Liu, et al., 2013). The water management module represents two typical water management activities: reservoir regulation/operation, and local water extraction/diversion. The focus of our reservoir regulation module is not on any individual reservoir but hundreds to thousands of reservoirs and their impacts on regional to global processes for earth system modeling.

140 It is almost impossible to obtain the actual operation rules of all the reservoirs. Nevertheless, some critical information of large reservoirs (e.g., storage capacity no less than $0.1 \mathrm{~km}^{3}$ ), such as the storage capacity and primary operating purposes, is available in some global datasets (Lehner et al., 2011). These large reservoirs can be classified into different categories based on their purposes, such as irrigation, flood-control, navigation, etc. For each reservoir category, we followed a generic algorithm to derive an operation rule for each reservoir based on the hydroclimate conditions in the upstream areas and the water demand

145 in the downstream areas (Li, Leung, Tesfa, et al., 2015; Voisin, Liu, et al., 2013). For example, for flood control purpose, reservoir release should follow a flat curve. For irrigation purpose, reservoir release should follow the seasonal variation of irrigation water demand.

\subsection{MOSART-sediment}

Riverine sediment load can be divided into two components: bed-material load and wash load (Biedenharn et al., 2006).

150 Wash load is the fraction of the moving sediment that cannot be found in the bed material with an appropriate fraction (Einstein et al., 1940; Lane, 1947) whereas bed-material load is the part that can be found substantially in the bed material. In other words, the bed material load is from the bed material and controlled by the local hydrodynamics and the bed material grain size. Wash load follows the fluid flow well without much exchange with the bed material and is thus controlled by the upstream 
supply. The bed-material load can be further divided into bedload and suspended part of bed-material load (suspended bedmaterial load) (Garcia (Ed.), 2008). Bedload refers to the coarse particles being transported in the vicinity of the river bed. Suspended bed-material load refers to particles being transported in suspension within the vertical column of the river flow and they interact with river beds usually after a relatively long suspended path in the fluid flow. Wash load often refers to the very fine particles, i.e., grain size less than $0.062 \mathrm{~mm}$ (Lane, 1947), which are usually in suspension, well mixed with water, and rarely reside on the river bed. Therefore, total suspended load consists of suspended bed-material load and wash load. This study focuses on total suspended load.

Because of the difference in their sources, bed-material load and wash load are modelled separately, and then the bedmaterial load is further divided into suspended bed-material load and bedload. In most rivers, particularly those large rivers, bed-material load consists of sand and gravel particles typically sourced from riverbeds. Wash load consists of silt and clay particles usually sourced from surface erosion at hillslopes. The transport processes of bed-material load and wash load are distinct and thus can be treated separately. Bed-material load is controlled by local hydraulic conditions and sediment particle size. Wash load is not constrained by local hydraulic conditions since channel flow usually has sufficient turbulent kinematic energy to suspend and transport wash load particles (silt and clay) (Garcia (Ed.), 2008; Moodie et al., 2020)..

Three primary components thus underpin MOSART-sediment: 1) a recently developed soil erosion module (Tan et al., 2018, 2020, 2021) for wash load supplied from hillslopes driven by overland flow, 2) a new riverine sediment module that treats wash load and bed-material load processes separately, and 3) a new reservoir module for reservoir effects on sediment transport. Next, we briefly describe the soil erosion module and provide details for the riverine and reservoir modules.

\subsubsection{Hillslope Sediment Processes}

The soil erosion module in the E3SM land model (ELM-Erosion) deals with two major processes: 1) detachment of soil particles (clay, silt, and sand) from topsoil (or soil erosion) by raindrops or overland flow, and 2) delivery of the detached soil particles along with overland flow from its location of detachment to rivers, during which the sand particles may deposit back to soil surface due to the limited transport capacity of overland flow. Here we only provide a brief description of these two processes and refer to more details in Tan et al. (2018).

The ELM-Erosion sediment yield model was developed based on the simple Morgan-Morgan-Finney (MMF) model (Morgan, 2001; Morgan \& Duzant, 2008), which is better suited for capturing the heterogeneous sediment yield at spatial and

180 temporal scales relevant to ESMs (several to hundreds of square kilometers in space and tens of minutes to hours in time) than other well-known models (Tan et al., 2018). This choice was made by applying and comparing the eight most extensively used sediment yield models at 454 small catchments in diverse environments across the United States, Canada, Puerto Rico, U.S. Virgin Islands and Guam. In our test, the MMF model can represent 53\% of the spatial variability of sediment yield over these catchments, which is much better than the other seven models, such as the Water Erosion Prediction Project (WEPP) model.

185 Our test also showed that the ELM-Erosion model could reproduce the observed daily sediment yield at six cropland-dominated catchments, with a relative error as low as $10 \%$ (Tan et al., 2018). Furthermore, the model is found to well capture the spatial variability of soil erosion and sediment yield among the U.S. states and large river basins (Tan et al., 2020). The ELM-Erosion 
model can account for the impacts of rainfall and runoff fluxes at the event scale and the impacts of vegetation dynamics such as changing leaf area index and canopy heights at the monthly or longer temporal scales. The ELM-Erosion has three parameters for calibration: a scaling factor parameter for rainfall-driven erosion, a scaling factor parameter for runoff-driven erosion, and a scaling factor parameter for sediment transport capacity. Following Tan et al. (2020), in this study, the ELMErosion model is calibrated at the state level over the conterminous U.S. using the National Resources Inventory (NRI) benchmark data and the pre-dam sediment yield data of large river basins.

Note that in the ELM-Erosion model, the distribution of soil particle size is not considered. Morgan \& Duzant (2008) revised the original MMF model (Morgan, 2001) to account for the sediment yield for clay, silt and sand particles, respectively. But we found in their comparison that this modification did not improve the model performance over the continental scale while introducing additional complexity and computational cost (Tan et al., 2018). Therefore, we chose to refine the MMF model directly for our sediment yield modeling. During a storm event, detachment could happen to either clay, silt, or sand soil particles. The transport capacity of overland flow for the detached soil particles across hillslopes decreases exponentially with increasing soil particle size (Morgan \& Duzant, 2008). A majority of detached sand particles will thus deposit back to the topsoil instead of entering the rivers. Therefore, it is reasonable to assume that wash load (silt and clay particles) is mainly from soil erosion at hillslopes (Garcia (Ed.), 2008; Patil et al., 2012).

\subsubsection{Riverine Sediment Processes}

The riverine sediment module focuses on suspended load and simulates suspended sediment process on top of the hydraulic conditions simulated by MOSART-water. The suspended load consists of the wash load and suspended bed-material load, which are treated separately.

Wash load is primarily carried by channel flow. For the sake of simplicity, we consider that the net sediment exchange between channel and floodplain is secondary as comparing to the riverine sediment discharge and thus negligible. The effects of reservoir processes on wash load are however nontrivial since reservoirs fundamentally slow down river flow in their immediate upstream channels. We detail the reservoir effects in Section 2.2.3.

Existing sediment transport formulas derived in sedimentology are mainly applicable to bed-material load and do not account for wash load (Garcia (Ed.), 2008). Most rivers can be roughly classified as gravel-bedded or sand-bedded rivers (Garcia (Ed.), 2008). Gravel-bedded rivers are usually located in mountainous headwater areas, where gravel and coarser material (e.g., pebbles and bounders) prevail in bed-material load and move mostly in bedload mode. Sand-bedded rivers are mostly in the lowland regions where the bed-material load is dominated by sand and finer particles, i.e., suspended bed-material load (Lamb \& Venditti, 2016).

Since this study focuses on suspended sediment, we mainly consider sand-bedded rivers and choose the sediment transport formula from those more suitable for sand-bedded rivers. The classic Engelund-Hansen equation (Engelund \& Hansen, 1967; Ma et al., 2020) is typically applicable over sand-bedded rivers and can be further extended to finer-grained rivers (Ma et al., 2017, 2020). It is one of the simplest formulas of bed-material load (Brownlie, 1983), and is relatively easy to estimate its parameters a priori, which is critically important for sediment simulation in an Earth system model setting at the regional or 
larger scales. Despite its simplicity, the Engelund-Hansen equation is one of the most accurate sediment transport formulas based on extensive validation against both laboratory and field observations (Brownlie, 1983; Church \& Ferguson, 2015; Crosato et al., 2011; Crosato \& Mosselman, 2009; Darby et al., 2002; Geleynse et al., 2011; Kleinhans et al., 2008; Lee et al., 1997; Ma et al., 2020; Mosselman, 1998; Nicholas, 2013; Schuurman et al., 2013; Simon \& Darby, 1997; Van Der Wegen \& Roelvink, 2008; Wiele et al., 1996). We therefore adopt the classic Engelund-Hansen equation as the governing equation for riverine bed-material sediment transport. Its implementation within MOSART-sediment is outlined below.

The total bed-material rate $Q_{\text {sand,total }}[\mathrm{kg} / \mathrm{s}]$ is given as

$$
Q_{\text {sand,total }}=\rho_{\text {sed }} B q_{s, \text { total }}^{*} \sqrt{\operatorname{Rg} D_{50}} D_{50}
$$

Where $\rho_{\text {sed }}=2650 \mathrm{~kg} / \mathrm{m}^{3}$ is the density of sediment, $B$ is the channel width [m], $R$ is submerged specific gravity for quartz in water $(R=1.65), g$ is the gravity acceleration rate $\left[\mathrm{m} / \mathrm{s}^{2}\right]$, and $D_{50}$ is the median grain size of bed-material sediment particles $[\mathrm{m}] . q_{s, t o t a l}^{*}$ is the dimensionless total sediment flux per unit width (denoted as the Einstein number) for bed-material load, expressed as

$$
q_{s, \text { total }}^{*}=\frac{0.05}{C_{f}}\left(\tau^{*}\right)^{2.5}
$$

where $C_{f}$ is the total resistance coefficient, and can be calculated from channel Manning's roughness coefficient, $n_{r}$, and channel hydraulic radius (in this study approximated as channel water depth $h$ ),

$$
C_{f}=\frac{\tau_{b}}{\rho v^{2}}=\frac{g n_{r}^{2}}{h^{1 / 3}}
$$

where $\rho$ is the density of water $\left[10^{3} \mathrm{~kg} / \mathrm{m}^{3}\right] ; \tau_{b}$ is the bed shear stress $[\mathrm{Pa}]$ and $\tau_{b}=\rho g h S_{r}$ in steady and uniform flows; $S_{r}$ is the local channel bed slope [-].

$\tau^{*}$ is the dimensionless shear stress (the Shields number), given as

$$
\tau^{*}=\frac{\tau_{b}}{\rho R g D_{50}}=\frac{C_{f} v^{2}}{R g D_{50}}
$$

where $v$ is the channel velocity $[\mathrm{m} / \mathrm{s}]$, and is estimated using Manning's equation (Manning, 1891).

$$
v=\frac{h^{2 / 3} s_{h}^{1 / 2}}{n_{r}}
$$

In the kinematic wave routing method, $S_{h}$ is taken as the local channel slope $S_{r}$. In the diffusion wave routing method, $S_{h}$ is estimated based on the difference in the simulated water surface elevations between the current and downstream channels.

Note that the Engelund-Hansen equation estimates the bed-material load that is the sum of bedload and suspended bedmaterial load. We adopt the transport-mode-parameter approach (Greimann et al., 2008) to separate the suspended bedmaterial load from the bed-material load computed by the Engelund-Hansen equation. The transport-mode-parameter approach specifies how much of a sediment size class is transported as bedload, suspended bed-material load, or mixed load following the "allocation coefficient" concept (Holly \& Rahuel, 1990). It is given as:

$$
f=\min \left(1,2.5 e^{-Z}\right)
$$


where $f(0 \leq f \leq 1)$ is the transport-mode-parameter, i.e., the portion of suspended sediment in the bed-material load. $Z$ is the suspension parameter and can be calculated as

$$
Z=\frac{\omega}{k u_{t}}
$$

where $\omega$ is sediment settling velocity $[\mathrm{m} / \mathrm{s}], u_{t}=\sqrt{g h S_{r}}$ is the frictional shear velocity [m/s], and $k$ is the von Kármán constant (0.41) [-].

Several formulas are available for sediment settling velocity, such as those named after Stokes (Zhang \& Xie, 1993), Zhang (Zhang \& Xie, 1993), Van Rijn (Rijn, 1989), and Cheng (Cheng, 1997), respectively. Cheng (1997) evaluated these formulas and suggested that Cheng's formula has the highest degree of prediction accuracy. It applies to a wide range of Reynolds numbers from the Stokes flow to the turbulent regime (Cheng, 1997). Thus, Cheng's formula is adopted in this study.

$$
\omega=\frac{v_{t}}{D}\left(\sqrt{25+1.2 d_{*}^{2}}-5\right)^{1.5}
$$

where $v_{t}$ is the kinematic viscosity of water at $20{ }^{\circ} \mathrm{C}\left(=1.036 \times 10^{-6} \mathrm{~m}^{2} \mathrm{~s}^{-1}\right)$, and $d_{*}$ is a dimensionless particle diameter, which is defined as:

$$
d_{*}=\left(\frac{g R}{v_{t}^{2}}\right)^{1 / 3} D_{50}
$$

The Engelund-Hansen equation assumes that sediment transport is always on capacity (equilibrium transport) (An et al., 2018, 2021; Engelund \& Hansen, 1967; Naito et al., 2019) This simplification is not unreasonable for large-scale river modeling since the travel distance from one reservoir to another is typically more than $10 \mathrm{~km}$. Such a spatial scale enables the sediment-laden flow to sufficiently interact with channel bed to reach transport capacity (An et al., 2018).

For comparison with the Engelund-Hansen equation, we also use another widely used formula to directly estimate the suspended sediment discharge rate, named after Wu (W. Wu et al., 2000) and well verified in multiple studies (Fang et al., 2017; Rousseau et al., 2016; Su et al., 2013; Sun et al., 2015; W. Wu et al., 2005). Wu's equation is given as:

$$
q_{s}^{*}=0.0000262\left[\left(\frac{\tau^{*}}{\tau_{c}^{*}}-1\right) \frac{v}{\omega}\right]^{1.74} \text { when } \tau^{*}>\tau_{c}^{*}
$$

where $q_{s}^{*}$ is the dimensionless sediment flux for suspended load; $\tau_{c}^{*}$ is the dimensionless critical shear stress above which sediment is mobilized (the default value is 0.0386).

\subsubsection{Reservoir Sediment Processes}

The reservoir sediment module incorporates both direct and indirect reservoir effects on sediment. The direct effect is the trapping of sediment within the reservoirs, preventing it from moving downstream. It applies to both wash load and bedmaterial load. The indirect effect is mainly through the reservoir regulation function simulated by MOSART-water, which modifies the hydraulic conditions, i.e., flow velocity, depth, and surface hydraulic gradient, in the downstream rivers of reservoirs. Therefore, it affects only bed-material load.

Reservoir trapping of sediment is mainly through fundamentally slowing down of the river flow upstream of dams. The slowing down of river flow in the reservoir essentially sets the transport capacity of sediment to near zero, leading to the settling of suspended sediment in the water column. Thus, the deposition rate (trapping rate) of suspended sediment is largely 
dependent on the settling time of suspended sediment in the reservoir. To this end, Brune (1953) developed an empirical formula for reservoir trapping efficiency and validated it for the U.S. reservoirs. It was later adopted globally (Syvitski et al., 2003, 2005; Vörösmarty et al., 2003). Here we also adopt Brune's formula to estimate individual reservoir trapping efficiency, $e_{\text {trap }}$ :

$$
e_{\text {trap }}=1-\frac{0.05}{\Delta T_{\text {local }}^{0.5}}
$$

where $\Delta T_{\text {local }}$ is the increase of local water residence time due to the reservoir [years], estimated as the effective reservoir storage capacity divided by the mean annual inflow from the reservoir's upstream. Other empirical formulas for reservoir trapping efficiency, e.g., Lewis et al. (2013), were also proposed but have not been tested at the regional or global scales. It is worth noting that the sediment trapping in the reservoir resulted from the settling of suspended sediment in a nearly-still water body, and it is thus applied to all the suspended sediment regardless of particle size. Brune (1953) and Lewis et al. (2013) assumed that wash load (silt and clay particles) and the suspended bed-material load (fine sand particles) were trapped by reservoirs in a similar way and did not differentiate them. Here we adopt the same assumption for simplicity. $e_{\text {trap }}$ gives the fraction of suspended load that is trapped in a reservoir, and the rest is released to downstream along with water.

The reservoir regulation effect on sediment is mainly by regulating river discharge, e.g., reducing high flow during a wet season and increasing low flow during a dry season. This flow regulation will modify riverine hydraulic conditions such as flow velocity and channel water depth, thus changing bed-material load transport capacity. Besides reservoir regulation, another water management activity represented in MOSART-water is surface water withdrawal which diverts channel water to somewhere else via artificial channels or pipes. For simplicity, we assume that surface water withdrawal reduces only water storage in channels but not sediment.

\section{Study Area, Data and Numerical Experiments}

\subsection{Study Area}

MOSART-sediment is designed to be applicable at the regional to global scales. In this study, we apply it over the contiguous United States (CONUS) for demonstration and validation, as shown in Figure 2. This study area is smaller than our previous study (Li, Leung, Tesfa, et al., 2015), where we applied ELM-MOSART driven by the atmospheric forcing data from the North American Land Data Assimilation System Data Phase 2 (NLDAS2) over central North America (Mitchell et al., 2004).

\subsection{Inputs and Parameters}

To support the MOSART-sediment application, we have derived several new parameters a priori over CONUS that are most critical to sediment transport, including sediment particle size, Manning's roughness coefficient, and channel geometry. These new parameters are meaningful mostly within CONUS since they have been derived based on various national databases. It is for this reason that our sediment modeling and analysis focus on CONUS. Note that, although the sediment modeling 
analysis focuses on CONUS, MOSART-water is still applied over the same larger domain as our previous study (Li, Leung, Tesfa, et al., 2015), which includes the Canadian portion of the Columbia River basin. Thus other MOSART-water parameters and inputs are adopted from this previous study.

The median bed-material sediment particle size, $D$, is the most important parameter for the Engelund-Hansen formula. In an earlier study (Abeshu et al., 2021), we derived a national map of the median bed-material sediment particle size $\left(D_{50}\right)$ over CONUS based on: 1) the observed sediment particle size data from USGS and the U.S. Army Corps of Engineering, 2) the comprehensive channel and catchment attributes from the National Hydrography Dataset Plus (NHDplus) (McKay et al., 2012; Schwarz et al., 2018), and 3) a predictive model established using state-of-the-art machine learning techniques (Chen \& Guestrin, 2016). The $D_{50}$ map from Abeshu et al. (2021) is in a vector format, i.e., each flowline in NHDplus is assigned a value of the median bed-material sediment particle size. In this study, the vector-format map is converted to the grid-based format at the $1 / 8^{\text {th }}$-degree resolution to be consistent with the other parameters, as shown in Figure 2a.

The channel geometry data, such as bankfull channel width and depth, are shown in Figures $2 \mathrm{~b}$ and $2 \mathrm{c}$. They are derived following a data-driven hydraulic geometry study (Bieger et al., 2015), which provided the empirical formulas for the whole contiguous U.S. Manning's roughness coefficient for river bed is derived based on an empirical formula estimating Manning's roughness coefficient as a linear function of channel water depth distribution within a river basin (Getirana et al., 2014; Luo et al., 2017), as shown in Figure 2d. Channel bed slope (Figure 2e) is essentially from the medium resolution NHDplus. In NHDplus, each flowline represents one river segment and is provided a channel slope value (along with many other channel attributes). We convert these NHDplus channel slope values from a vector format to a grid-based format here. First, the NHDplus flowlines are georeferenced to the MOSART lat/lon grids at the $1 / 8^{\text {th }}$-degree resolution in two steps: 1 ) local matching and 2) neighborhood matching. For the local matching, we adjust the geographic locations of the downstream ends of the NHDplus flowlines to the MOSART grids center. The drainage areas associated with the NHDplus flowlines (in a vector-based river network) are then compared against those associated with the corresponding MOSART grids (in a gridbased river network). The neighborhood matching is performed only for those grids where the margin of error is significant (>20\% of NHDplus drainage area). Neighborhood matching is to re-adjust the flowlines from the current MOSART grid cell to one of the 8-neighboring cells where the NHDplus-MOSART drainage area difference is minimal. Then we associate each

340 MOSART-water grid with a single NHDplus flowline. Hence, in the case of multiple flowlines per grid, which is very common, we choose the flowline that has a drainage area closest to the MOSART grid. After the above procedure, each MOSART grid is associated with a flow line. The channel slope of each MOSART grid is then taken as the channel slope value from the corresponding flow line. Reservoir storage capacity (Figure 2f) is already available from our previous study (Li, Leung, Tesfa, et al., 2015) but also critical for sediment modeling, so we display them here for completeness.

345 The observed monthly suspended sediment discharge and streamflow from the United States Geological Survey (USGS) river gauges are used to validate the model performance. We choose to validate the model at the monthly scale instead of finer scales due to two considerations: 1) The biases in the streamflow simulations by ESMs and even other land surface models are already noticeable at the monthly scale (Getirana et al., 2014, 2021; Li, Leung, Getirana, et al., 2015; Mizukami et al., 2021). 
2) The sampling of riverine sediment by USGS is not continuous like the streamflow measurement (taken automatically at an hourly or even shorter time step), but rather infrequently due to the required field visits and subsequent sample analysis (Groten \& Johnson, 2018). There is thus considerable uncertainty in the daily suspended sediment data from USGS. Figure 3a shows the locations of 35 selected USGS river gauges along with the river networks (displayed in the form of accumulated upstream drainage area at $1 / 8^{\text {th }}$-degree resolution). Table 1 also provides more details of these selected gauges. These 35 USGS gauges are selected based on three criteria: 1) a no-more-than-20\% difference between the actual upstream drainage area (reported by USGS) and the area represented within a grid-based river network, 2) at least five years of both monthly streamflow and suspended sediment observations in our study period 1990-2012 (see Section 4.1 for the reasons of choosing this period), and 3) relative bias of MOSART-water streamflow simulation (using the full modeling capacity) no more than 50\% in 1990-2012. The last criterion is to control the impacts of runoff and streamflow simulation uncertainty to a certain level. There are 63 gauges meeting the first two criteria. When considering the third criterion, the number drops from 63 to 35 , suggesting that there is still large uncertainty in the runoff and streamflow simulation in E3SM. In fact, the uncertainty in runoff and streamflow simulation remains a challenge in Earth System modeling (Lawrence et al., 2019) and fully addressing it is beyond the scope of this study. Among the selected gauges, their upstream drainage areas vary between $1225 \mathrm{~km}^{2}$ to $1850000 \mathrm{~km}^{2}$, covering a range of spatial scales.

Three representative USGS gauges (shown as the red stars in Figure 3b) are chosen out of the 35 gauges for more detailed analysis, including USGS05586100 Illinois River at Valley City in Illinois (ILV), USGS06807000 Missouri River at Nebraska City in Nebraska (MON), and USGS07022000 Mississippi River at Thebes in Illinois (MST). The choice of these three gauges is based on two considerations: 1) these gauges are subject to different levels of reservoir effects, and 2) the drainage areas of these gauges are relatively larger than the others, hence more representing large rivers. The upstream drainage areas for ILV, MON, and MST are $6.93 \times 10^{5} \mathrm{~km}^{2}, 1.06 \times 10^{6} \mathrm{~km}^{2}$, and $1.85 \times 10^{6} \mathrm{~km}^{2}$, respectively. In this study, we use $\Delta T_{\text {basin }}$, the increase of average river water residence time due to all the reservoirs in the upstream areas of a lat/lon grid, to approximate the total reservoir effects including flow regulation and trapping, i.e., the larger the $\Delta T_{\text {basin }}$ value, the stronger the reservoir effects. Note that $\Delta T_{\text {basin }}$ is different from $\Delta T_{\text {local }}$ in Eqn. (11). For any lat/lon grid, $\Delta T_{\text {basin }}$ is calculated as ratio of the sum of storage capacity of all the reservoirs in its upstream areas over the long-term average inflow to this grid. $\Delta T_{\text {basin }}$ closely corresponds to the reservoir regulation index, the ratio of total upstream reservoir storage capacity to the annual streamflow volume (annual

375 mean flow multiplied by the time of a year), which has been used as an indicator of reservoir flow regulation effects (Wang et al., 2017). As shown in Figure 3b, MON and ILV are subject to strong and weak reservoir effects, respectively. MST is downstream of MON and ILV and subject to moderate reservoir effects.

\subsection{Numerical Experiments}

The simulation period is 1979-2012 due to the availability of model inputs, particularly the monthly water demand data 380 that were derived in our previous study (Li, Leung, Tesfa, et al., 2015). ELM-Erosion is applied to 1979-2012 driven by the NLDAS2 atmospheric forcing at the $1 / 8^{\text {th }}$-degree resolution to generate both daily sediment yield and daily runoff time series 
at each $1 / 8^{\text {th }}$-degree grid as the inputs for MOSART-sediment. All the soil erosion parameters are adopted from Tan et al. ( 2021). Note that Tan et al. (2021) accounted for both climate and land-use change impacts on soil erosion. In this study, we do not consider land-use change, i.e., assuming static landuse. Using the daily inputs from ELM-Erosion, we run MOSARTsediment in 1979-2012 at a daily time step and a 1/8 ${ }^{\text {th }}$-degree spatial resolution. We consider 1979-1989 as the model spin-up period and carry out the model validation and analysis in 1990-2012.

To isolate the relative contributions of reservoir regulation and trapping processes to suspended sediment transport, three major numerical simulations are designed: 1) sim_nat, MOSART-sediment is run under natural river conditions only, i.e., no reservoir regulation or trapping; 2) sim_wm_only, MOSART-sediment is run with the water management option, but turning off reservoir trapping; 3) sim_wm_trapping, MOSART-sediment is run with the water management option to include both flow regulation and reservoir trapping effects. The individual effects of reservoir regulation and trapping can be estimated by

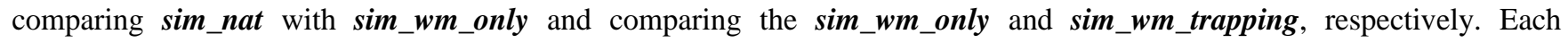
simulation is driven by the same sediment yield time series for the period of 1979-2012. Note that the suspended bed-material load in these three major experiments is estimated using the Engelund-Hansen equation, and main channel routing is simulated using the diffusion wave routing method.

We also perform additional numerical experiments to understand the sensitivity of modeling results to the key model parameters, compare the Engelund-Hansen equation with the $\mathrm{Wu}$ formula, and compare the diffusion wave routing method with the kinematic wave routing method. More details of these additional numerical experiments will be provided later. Note that in all these numerical experiments, no parameter calibration is conducted for the riverine component. All related parameters have been estimated a priori.

\section{Modeling Results}

\subsection{Model Validation}

MOSART-sediment captures the significant spatial heterogeneity in total suspended load, wash load, and suspended bedmaterial load, respectively, as shown in Figure 4 where the maps are generated from the sim_wm_trapping simulation results.

405 The spatial patterns of total suspended load are determined by the patterns of wash load, suspended bed-material load, and their relative dominance at different locations. It appears that suspended bed-material load dominates in the western U.S., e.g., the Columbia and Colorado River basins. Wash load dominates in east of the Rocky Mountains, e.g., the Mississippi River basin, and coastal areas of northeastern U.S. We use the percentage of wash load in the total suspended load to illustrate the relative dominance of wash load at each lat/lon grid, as shown in Figure 4e. In this study, the model simulated spatial average 410 of the wash load percentage is $62.2 \%$, with higher values in the central and eastern U.S. and coastal western U.S. The dominance of wash load in the simulated suspended load is consistent with previous data-driven studies. For example, Sadeghi and Singh (2017) analyzed the observed suspended load at 24 USGS gauges distributed throughout CONUS and suggested 
that wash load dominate in the majority of these gauges, i.e., the percentage of wash load in the total suspended load is 79.085 $\pm 11.343 \%$ over these gauges.

The spatial heterogeneity of simulated wash load is controlled mainly by that of sediment yield and the spatial distribution of reservoirs. More sediment yield can be from more humid or mountainous areas since it is triggered primarily by surface runoff and raindrops. Reservoir trapping significantly reduces the amount of wash load carried to the rivers downstream of reservoirs. The supply of sand sediment is mostly from the in-channel process, as a function of grain size, channel geometry, and hydraulic conditions such as the shear stress and channel velocity. Roughly, the sand discharge is large when the channel water depth is deep, the channel bed slope is steep, or Manning's roughness coefficient is small. Reservoir regulation reduces the high flow during the wet season and then reduces suspended bed-material load by reducing channel water depth and velocity in the rivers downstream of reservoirs. However it enhances the low flow during the dry season and increases suspended bed-material load in the rivers downstream of reservoirs, which is consistent with the findings reported from literature (Naito et al., 2019; Nittrouer \& Viparelli, 2014). Reservoir trapping appears to have little effect on the simulated suspended bed-material load. Reservoirs prevent the upstream suspended bed-material load from going downstream. But the reduced suspended bed-material load is supplemented by the local channel erosion in downstream rivers. Recall the assumption underpinning the Engelund-Hansen equation that the local supply of suspended bed-material load is unlimited.

MOSART-sediment reasonably well captures the long-term average suspended sediment discharge values across CONUS, as shown in Figure 5 for comparison between the model simulated and observed annual mean values in 1990-2012 at multiple USGS gauges. Here the comparison is also shown between the sim_nat and sim_wm_trapping simulations. The model performs very well in simulating the long-term streamflow over the selected 35 gauges. The difference in streamflow between sim_nat and sim_wm_trapping is negligible, which is reasonable because 1) reservoir trapping does not affect streamflow at all and 2) reservoir regulation changes mostly intra-annual variability of streamflow and sometimes inter-annual variability, but the long-term mean streamflow is largely unaffected. For suspended sediment, the simulated annual mean values are overall close to those observed, as indicated by the close alignment of the dots with the 1:1 line, particularly for sim_wm_trapping. Fitted lines are included in Figure 5 to help visualize the overall patterns. The $\mathrm{R}^{2}$ values between the simulations and observations are 1.0 for the streamflow from both sim_nat and sim_wm_trapping, and 0.6 for the suspended sediment from both $\boldsymbol{s i m} \_n a t$ and $\boldsymbol{s i m} \_w \boldsymbol{w} \_$trapping respectively. WBMsed was validated over CONUS at 11 USGS gauges in 1997-2007 with an overall satisfactory performance (see Fig. 7 in Cohen et al., 2013). WBMsed nevertheless overestimated the long-term average suspended load over the four largest gauges on the Mississippi River (here "largest" means the gauges with the largest suspended load observations), whilst our model seems to have less overestimation over the largest gauges, e.g., Mississippi River at Thebes (USGS ID 07022000). Comparing Fig. 7 in Cohen et al. (2013) with Fig. 5 in this study, one can infer that our model performance is comparable to WBMsed.

We further use the Kling-Gupta coefficient (KGE) (Gupta et al., 2009) and the normalized-root-mean-square (NRMSE) 445 to evaluate the model simulated long-term average across multiple gauges. KGE is a comprehensive metric that integrates the effectiveness of previous extensively used metrics such as root-mean-square-error and the Nash-Sutcliffe coefficient (NSE). 
It thus captures both the magnitude and timing (or phase) difference between two temporal or spatial series. KGE ranges from negative infinity to 1.0, with 1.0 indicating perfect model performance (Gupta et al., 2009). It has been suggested that a KGE value higher than -0.41 implies that a model performs better than the long-term mean benchmark, i.e., equivalent to NSE=0 (Knoben et al., 2019). NRMSE is calculated as the ratio of RMSE over the long-term mean of a temporal or spatial series. For streamflow, KGE increases from 0.89 to 0.96 and NRMSE decreases from 0.24 to 0.12 by including the reservoir effects, i.e., from sim_nat to sim_wm_trapping. For suspended sediment, KGE increases from - 0.40 to 0.69 , and NRMSE decreases from 2.35 to 0.74 by including the reservoir effects. Overall, Figure 5 suggests a very good model performance in capturing the long-term suspended sediment balance across different spatial scales. It also suggests that adding the reservoir effects improves the simulated long-term suspended sediment loads more significantly than the simulated long-term streamflow over the selected gauges.

We further evaluate the model performance at the monthly scale using the KGE values between the simulated and observed monthly time series. We roughly classify the KGE values at the 35 gauges into three categories: Category I, KGE $\leq-0.41$, poor model performance; Category II, $-0.41<\mathrm{KGE} \leq 0$, decent model performance; Category III, KGE $>0$, good model performance. Figure 6 displays the spatial distribution of the KGE values based on the sim_wm_trapping simulation. For streamflow, 0, 1, and 34 of the 35 USGS gauges have KGE values in Category I, II, and III, respectively. For suspended sediment, 10, 7, and 18 gauges have KGE values in Category I, II, and III, respectively. Table 1 lists the specific KGE and NRMSE values between the monthly simulated and observed streamflow and suspended sediment time series at each gauge based on the sim_wm_trapping simulation. Note that the availability of monthly observations varies between different gauges. Overall,

465 MOSART-sediment has a decent or good performance at over 25 of the 35 gauges, indicating that the model is able to capture reasonably well the intra-annual variability of suspended sediment in large river systems.

Compared to streamflow, model biases in the suspended sediment are noticeably larger. Figure 5 suggests that MOSARTsediment overall overestimates annual mean suspended sediment load in many gauges. Figure 6 also suggests poor model performance at some gauges. There are several possible reasons for these biases: 1) We have only included $\sim 1800$ large reservoirs (storage capacity no less than $0.1 \mathrm{~km}^{3}$ ) with critical information (storage capacity, location, major purposes, etc.) publicly available from the Global Reservoir and Dam Database (GRanD) (Lehner et al., 2011). Relatively small reservoirs in CONUS are not included in the model inputs due to a lack of necessary information, which will be addressed in future work.

2) There are noticeable biases already in the runoff and streamflow simulation at the monthly or shorter time scales, as shown in Figure 7, which propagate to the suspended sediment simulations. 3) There are uncertainties in the model structure and model parameters such as sediment particle size, channel slope, etc., which we will discuss next.

\subsection{Uncertainty Analysis}

\subsubsection{Model Structure Uncertainty}

MOSART-sediment simulates hillslope, riverine, and reservoir processes. Here we focus on the riverine and reservoir processes. Uncertainties in the hillslope process (e.g., soil erosion) were discussed in previous studies (Tan et al., 2018, 2021). 
For the simulated riverine processes, we mainly analyze the uncertainties in the sediment governing equations and routing methods. The accuracy of suspended sediment simulation could be affected by the choice of sediment transport equations and simulation of riverine hydraulic conditions. Many sediment transport equations, like Engelund-Hansen and Wu's equations, are well-established in the laboratory or single-reach scale. The implementations of such sediment transport equations at a regional scale for morphology simulation purposes are also well established (Naito et al., 2019; Nittrouer et al., 2012). Their applications in simulating suspended sediment at the continental scale are nevertheless rarely reported. Note our previous major experiment, sim_wm_trapping, uses the diffusion wave routing method and Engelund-Hansen equation. To compare the performance of Engelund-Hansen and Wu's equations in combination with different routing methods, we have conducted three additional numerical experiments. These three additional experiments all include the reservoir regulation and trapping effects. One of them uses the diffusion wave routing method and Wu's formula. The other two use the kinematic wave routing method, but Engelund-Hansen and Wu's formulas, respectively.

Figure 7 shows the KGE and NRMSE values of the simulated monthly suspended sediment load over the selected gauges. Note that Figure 7a only displays the gauges with their KGE values within -1.0 1.0 for clarity. For other gauges, uncertainties in the governing equations and routing methods are secondary to other sources of uncertainties, i.e., in the runoff scheme, channel geometry and other parameters. Figure $7 \mathrm{~b}$ includes all of the 35 gauges. Over some gauges, the Engelund-Hansen equation (plus the transport-mode-parameter approach) performs better than $\mathrm{Wu}$ 's formula, particularly as indicated by the significantly decreased KGE and increased NRMSE values over some gauges. The long-term KGE and NRMSE values between the simulated and observed suspended load over the selected gauges are 0.29 and 1.76 respectively when using Wu's formula and diffusion wave method, both are worse than those using the Engelund-Hansen equation and diffusion wave method. Therefore, the Engelund-Hansen equation (plus the transport-mode-parameter approach) overall outperforms Wu's formula.

As for the routing methods, it appears that the difference between the sediment simulations using the diffusion wave routing method and those using the kinematic wave routing method is overall less than the difference between the EngelundHansen and Wu's formulas. The difference between the monthly streamflow simulations using different routing methods is even more negligible (Figure not shown). At the 35 selected stations located mostly upstream of river outlets, the backwater effects are likely not dominant. In flat locations such as close to the river mouths, however, the backwater effects are expected to be significant, and as such using the diffusion wave routing method should lead to better performance in not only the streamflow but also the sediment simulations.

For the reservoir process, we analyze the uncertainties in the reservoir regulation and trapping processes. Figure 8 illustrates the total impacts of the two reservoir processes by contrasting the sim_nat and sim_wm_trapping simulations results

510 at the three representative gauges subject to different levels of reservoir effects. At ILV, whose upstream drainage area is subject to relatively small reservoir effects, there is a negligible difference between the simulated streamflow from sim_nat and sim_wm_trapping, indicating relatively minor water management activities in the upstream areas due to a relatively smaller number of reservoirs and low water demand. At MON, its upstream drainage area is subject to strong reservoir effects. 
The simulated streamflow is significantly reduced from sim_nat to sim_wm_trapping particularly over the high-flow periods

in the summer, mainly due to the intensive surface water extraction in the upstream drainage area and the strong reservoir regulation effect. At MST, whose upstream drainage area is subject to moderate reservoir effects, the simulated streamflow is also noticeably reduced from sim_nat to sim_wm_trapping during the high-flow periods. At all these gauges, the simulated suspended load is significantly reduced from sim_nat to sim_wm_trapping by reservoir trapping. In the upstream area of ILV, there are only a few reservoirs simulated. These reservoirs, however, can still trap a large portion of suspended sediment, suggesting that the effects of reservoirs on suspended sediment discharge are likely more significant than those on streamflow.

Figure 9 displays the change of KGE for the monthly streamflow and suspended load at all selected USGS gauges from sim_nat to $\boldsymbol{s i m} \_w \boldsymbol{w} \_$trapping. After adding the reservoir effects (sim_wm_trapping), the model performance is significantly improved (KGE increases more than 0.05) at 5 and 23 of the 35 USGS gauges for streamflow and suspended load simulations, respectively, and worsened at 12 and 2 USGS gauges, respectively. For the remaining gauges, the change of model performance is negligible. For streamflow, the model performance is already quite good even for sim_nat in terms of the monthly streamflow simulation (see Fig. 5 and Table 1). The uncertainties in the runoff generation, routing structures and parameters appear to overshadow the benefits of adding water management, hence leading to worsened model performance at 12 gauges. The improvement of sediment simulation by adding both reservoir regulation (as part of water management) and trapping is obviously more dominant. Figures 8 and 9 only show the combined effects of reservoir regulation and trapping, as interpreting their individual effects is not straightforward.

The net effects of reservoir regulation and trapping are further examined in Figure 10 by comparing the mean monthly streamflow and suspended sediment discharges among the sim_nat (blue lines), sim_wm_only (green lines), sim_wm_trapping (black lines) simulations. By comparing the blue and green lines, one can see the effects of flow regulation caused by water management. Overall, the net effects of reservoir operations on streamflow are to reduce the high-flow in the wet season (May to August) and increase the low-flow in the dry season, and these effects are relatively minor on the flow discharge at ILV, significant at MON, and moderate at MST. Reservoir regulation also reduces the suspended sediment discharge, but the effects are only noticeable during the high-flow period and negligible over the low-flow period when the sediment load is already low. By comparing the green and black lines in Figure 10, one can see the net effects of reservoir trapping. Reservoir trapping largely reduces the magnitude of suspended sediment discharge across all three gauges, including ILV where the reservoir regulation effect seems minor. After adding reservoir trapping, the simulated sediment discharge is much closer to the observations at all three gauges.

The effect of reservoir regulation on streamflow can be propagated from one reservoir to another downstream in a cascading manner. This is because reservoirs do not store water in the long term but only hold it for a short period (i.e., a few months) and then release it downstream. The effects of reservoir trapping may propagate from upstream to downstream for wash load but not for suspended bed-material load. For wash load, reservoirs intercept and keep most of it without releasing it to the downstream reservoirs. Hence, the trapping effect propagates downstream. For suspended bed-material load, even if reservoirs trap most of it from upstream inflow, the downstream river channel beds and in-channel bars will be eroded to 
supply suspended bed-material load to maintain a dynamic equilibrium state between the in-channel erosion and deposition. This way, the transport rate of bed-material load in the river downstream of a reservoir is only limited by the local hydraulic conditions, i.e., according to the Engelund-Hansen equation.

Although including reservoir trapping improves the simulation of suspended sediment discharge, there are still some discrepancies between the simulations and observations, such as the underestimation of sediment discharge in January-April (at ILV and MST) and overestimation in July-October (at all three gauges). These discrepancies between the simulated and observed seasonal variations in the suspended sediment discharge are likely not due to the streamflow biases. Besides possible uncertainties in the sediment model parameters, another probable cause of the model biases in sediment discharge is that the Brune formula adopted in this study estimates the long-term average reservoir trapping coefficient without explicitly accounting for the seasonal variation in the trapping efficiency (Brune, 1953).

\subsubsection{Model Parameter Uncertainty}

Here we present model parameter uncertainty analysis focusing on three important and representative parameters: median bed-material sediment particle size, $D$, channel slope, $S_{r}$, and Manning's Roughness coefficient for channels, $n_{r}$. $D$ is involved in multiple riverine sediment processes (e.g., Eqn. (1), (4), (8), and (9)). $S_{r}$ and $n_{r}$ affect the sediment processes both directly and indirectly (e.g., Eqn. (3)-(5)). Other parameters are not included here for simplicity.

Figure 11 shows the changes in the simulated long-term average suspended load in 1990-2012 (based on sim_wm_trapping) after increasing or decreasing $D, S_{r}$, and $n_{r}$ by $10 \%$ respectively. The spatial patterns of these changes are largely controlled by the spatial patterns of the simulated wash load and suspended bed-material load (see Figure 4). $D, S_{r}$, and $n_{r}$ are mostly affecting the riverine hydraulic conditions and not much wash load transport. The changes in the total suspended load are thus only significant over places dominated by the suspended bed-material load. For places dominated by wash load, the changes in the total suspended load are overall small or even negligible. In fact, the median percentage changes in the suspended load are mainly in the range of $-2 \%$ 2\% for all three parameters (Figure 13). Comparing among the three parameters, the simulation of the suspended bed-material load is most sensitive to the changes in $S_{r}$, followed by $D$, and least sensitive to the changes in $n_{r}$.

\subsection{Impacts of reservoirs on suspended sediment discharge to the coasts}

Despite the uncertainties, MOSART-sediment is a useful tool to shed light on some interesting questions. For example, how will reservoirs affect fresh water and suspended sediment discharges to the coasts? Figure 13 shows the model-simulated impacts of water management on freshwater discharge (Figure 13a) and the effects of reservoirs on suspended sediment discharge (Figure 13b) to the coasts. Note that in Figure 13b, we focus on wash load only instead of total suspended load, i.e., excluding the suspended bed-material load. There are three reasons: 1) Wash load consists of very fine particles and is a major carrier of carbon and nutrients from land into rivers and then to the coasts. 2) Wash load is dominant in most rivers. 3) Wash load is subject to the impacts of both upstream drainage areas (e.g., land use change, water management, precipitation) and 
580 local channel conditions (e.g., channel slope, $D_{50}$ ), whilst suspended bed-material load is mostly dominated by the local channel conditions.

According to our simulations, water management moderately reduces the freshwater discharge to the coasts, particularly for the smaller rivers on the southwest coasts (Figure 13a). The major cause of reduction in freshwater discharge is surface water extraction (which is mainly controlled by water demand intensity) since reservoir regulation normally does not reduce streamflow on a decadal scale (e.g., in the period of 1990-2012). The reduction of freshwater discharge to the southwest coasts is thus consistent with the high irrigation water demand over the western U.S., e.g., in the Colorado river basin.

The delivery of suspended sediment from the continental U.S. to the coasts is reduced more significantly than streamflow (Figure 13b). According to our simulation results, the reduction of suspended load by reservoirs is high (e.g., over 95\%) in some river basins such as Colorado and Brazos River but medium or low in other rivers such as the Mississippi and Columbia River. The former rivers have a large proportion of wash load relative to the total suspended load (indicated by the colors of the circles). As such, the reservoir trapping effect plays a vital role. In many small rivers close to the coasts but not subject to reservoir effects, most of their suspended sediment discharge is delivered to the coasts without being trapped during the transport. We do not find any notable relationship between the percentage reductions in streamflow vs. those in suspended sediment discharge at the river mouths. For the former, surface water extraction is the major cause; whilst for the latter, 595 reservoir trapping is the major cause. These two major causes do not directly interact with each other, suggesting that the reduction of suspended sediment discharge may not be closely linked to the reduction of streamflow. These inferences, however, are made based on the simulation results, and further investigations using more comprehensive observational datasets and modeling approaches are needed in the future. Moreover, we caution that the wash load estimates (with sim_wm_trapping) do not account for the effects of small reservoirs, and are likely higher than the real conditions.

600 Nevertheless, our estimates of wash load from large rivers to the coasts are comparable with previously reported numbers. Within the conterminous United States, the greatest amount of sediment is transported by rivers within the Gulf of Mexico drainage system. Meade and Moody (2010) reported that in 1987-2003, the Mississippi River system on average discharged 172 Million-tons/year total suspended load to the coast, which is moderately less than our wash load estimation of 228.23 Million-tons/year from sim_wm_trapping (used in all the comparisons below unless stated otherwise). Holeman (1968)

605 estimated that the Columbia River discharged about 9 Million tons of total suspended load per year to the Pacific Ocean, and 15 years later, this magnitude was reported to be reduced to 8 Million tons/year (Meade \& Milliman, 1983). Wise et al. (2007) also estimated 5.1 Million tons of suspended sediment delivery during an average water year. Our wash load estimate for the period 1990-2012 is 6.34 Million-tons/year from the Columbia River to the Pacific coast. For other river systems, our estimates for the period of 1990-2012 are less than the reported suspended load estimates which were made decades ago. For the Brazos

610 River, one of the largest rivers after the Mississippi River in terms of sediment load delivered to the Gulf of Mexico, Holeman (1968) estimated 32 Million tons/year of the total suspended load. A decade later, Milliman and Meade (1983) estimated it to be 16 Million-tons/year, a much-reduced value. Our wash load estimate is 1.55 Million-tons/year, even further reduced, which 
is possible given that there has been a decreasing trend of suspended sediment discharge in the U.S. river systems over the past few decades due to improved soil erosion controls (Meade \& Moody, 2010).

\section{5. Summary and Conclusion}

In this study, a new large-scale suspended sediment module has been developed on top of MOSART within E3SM. Both reservoir trapping and regulation mechanisms have been incorporated. Validation of the model simulations against the observations from 35 USGS gauges located across the contiguous United States shows reasonable skill in simulating the longterm average suspended sediment discharge $(\mathrm{KGE}=0.69, \mathrm{NRMSE}=0.74)$ and monthly suspended load (KGE $>0$ in 18 of the 35 gauges). We show that adding the reservoir effects improves the model simulations, particularly at the annual and monthly scales. As such, our model performance is comparable to WBMsed without any calibration. We carry out the model uncertainty analysis in terms of the model structure and parameter uncertainties. We further show that reservoir trapping exerts dominant effects (over reservoir regulation) on suspended sediment discharge through large river systems to the coasts.

The analyses help identify several opportunities to further advance large-scale suspended sediment modeling, including but not limited to: (1) improving the runoff and streamflow simulation within the Earth system modeling framework; (2) effectively accounting for the intra- or inter-annual variations in the reservoir trapping efficiency over multiple reservoirs at the regional or global scales; (3) including the effects of small reservoirs on streamflow and sediment simulations; (4) improving the accuracy of channel bed slope estimation. Moreover, our separate treatment of wash load and bed-material load will make it easier to isolate various climate and human impacts on riverine sediment. For instance, water management such as local channel water withdrawal and reservoir operation will primarily affect bed-material load by modifying hydraulic conditions. Land management such as land-use change and farming activities will affect wash load by changing topsoil erosional conditions. Lastly, for the sediment particle size, we have developed adopted a spatial map of median bed-material sediment particle size to support the parameterization of the sediment governing equations but there is still room to enhance the accuracy and availability of the sediment particle data through improved understanding and more data collection. Each of these opportunities above requires a chain of efforts to achieve and is thus beyond the scope of this work.

While future opportunities exist to further improve MOSART-sediment, this study presents a new process-based sediment modeling framework from a coupled earth-human system perspective. It has the potential to enable investigations that were not possible on the suspended sediment delivery to the coasts under various disturbances induced by variability and changes in climate and human activities. For example, the models can be used to explore how extreme events such as floods and

640 droughts and their long term changes may influence sediment delivery to the coast and hence the biogeochemistry of the coastal ecosystem, and the role of soil erosion and sediment transport in atmospheric $\mathrm{CO}_{2}$ through changes in the terrestrial, riverine, and ocean biogeochemistry. Finally and importantly, the new sediment module lays the foundation for modeling transportation and transformation of particulate $\mathrm{C}, \mathrm{N}$, and $\mathrm{P}$ through the river-ocean continuum to help close the global C, N, and $\mathrm{P}$ cycles within Earth system models. 
https://doi.org/10.5194/hess-2021-491

Preprint. Discussion started: 30 September 2021

(c) Author(s) 2021. CC BY 4.0 License.

\section{Code Availability}

The source code developed in this study is available through the E3SM GitHub repository (https://github.com/E3SMProject/E3SM/tree/hongyili/mosart/mosart-sediment-v2).

\section{Data Availability}

The data used in this study will be available upon request to the corresponding author.

\section{Author Contribution}

HL developed the code, carried out the simulations and wrote the manuscript draft. HL, ZT, HM, ZZ, SZ, SC all contributed to the methodology. HL, ZZ and LRL performed the analysis. GA, TZ and DX helped with the model inputs and observational data processing. HL and GA prepared the figures. All authors contributed to the writing and discussion.

\section{Competing Interest}

655 The authors declare that they have no conflict of interest.

\section{Acknowledgment}

This research is supported by the Office of Science of the U.S. Department of Energy as part of the Earth System Model Development program area through the Energy Exascale Earth System Model (E3SM) project. The Pacific Northwest National

660 Laboratory is operated by Battelle for the U.S. Department of Energy under Contract DE-AC05-76RLO1830. The source code from this study will be publicly available through the E3SM GitHub repository (https://github.com/E3SM-Project/E3SM). 


\section{References}

Abeshu, G. W., Li, H.-Y., Zhu, Z., \& Leung, L. R. (2021). Median bed-material sediment particle size across rivers in the contiguous U.S. Earth Syst. Sci. Data Discuss. https://doi.org/10.5194/essd-2021-201

An, C., Gong, Z., Naito, K., Parker, G., Hassan, M. A., Ma, H., \& Fu, X. (2021). Grain Size-Specific Engelund-Hansen Type Relation for Bed Material Load in Sand-Bed Rivers, With Application to the Mississippi River. Water Resources Research, 57(2). https://doi.org/10.1029/2020WR027517

An, C., Moodie, A. J., Ma, H., Fu, X., Zhang, Y., Naito, K., \& Parker, G. (2018). Morphodynamic model of the lower Yellow River: Flux or entrainment form for sediment mass conservation? Earth Surface Dynamics, 6(4), 989-1010. https://doi.org/10.5194/esurf-6-989-2018

Berhe, A. A., Barnes, R. T., Six, J., \& Marín-Spiotta, E. (2018). Role of Soil Erosion in Biogeochemical Cycling of Essential Elements: Carbon, Nitrogen, and Phosphorus. Annual Review of Earth and Planetary Sciences, 46(March), 521-548. https://doi.org/10.1146/annurev-earth-082517-010018

Biedenharn, D. S., Thorne, C. R., \& Watson, C. C. (2006). Wash Load/Bed material load concept in regional sediment management. Eighth Federal Interagency Sedimentation Conference.

Bieger, K., Rathjens, H., Allen, P. M., \& Arnold, J. G. (2015). Development and Evaluation of Bankfull Hydraulic Geometry Relationships for the Physiographic Regions of the United States. Journal of the American Water Resources Association, 51(3). https://doi.org/10.1111/jawr.12282

Brownlie, W. R. (1983). Flow Depth in Sand-Bed Channels. Journal of Hydraulic Engineering, 109(7). https://doi.org/10.1061/(asce)0733-9429(1983)109:7(959)

Brune, G. M. (1953). Trap efficiency of reservoirs. Eos, Transactions American Geophysical Union, 34(3). https://doi.org/10.1029/TR034i003p00407

Caldwell, P. M., Mametjanov, A., Tang, Q., Van Roekel, L. P., Golaz, J.-C., Lin, W., Bader, D. C., Keen, N. D., Feng, Y., Jacob, R., Maltrud, M. E., Roberts, A. F., Taylor, M. A., Veneziani, M., Wang, H., Wolfe, J. D., Balaguru, K., CameronSmith, P., Dong, L., ... Zhou, T. (2019). The DOE E3SM Coupled Model Version 1: Description and Results at High Resolution. Journal of Advances in Modeling Earth Systems, 11(12). https://doi.org/10.1029/2019MS001870

Chen, T., \& Guestrin, C. (2016). XGBoost: A Scalable Tree Boosting System. Proceedings of the 22nd ACM SIGKDD International Conference on Knowledge Discovery and Data Mining. San Francisco, California.

Cheng, N.-S. (1997). Simplified Settling Velocity Formula for Sediment Particle. Journal of Hydraulic Engineering, 123(2). https://doi.org/10.1061/(asce)0733-9429(1997)123:2(149)

Church, M., \& Ferguson, R. I. (2015). Morphodynamics: Rivers beyond steady state. Water Resources Research, 51(4). https://doi.org/10.1002/2014WR016862

Cohen, S., Kettner, A. J., \& Syvitski, J. P. M. (2014). Global suspended sediment and water discharge dynamics between 1960 and 2010: Continental trends and intra-basin sensitivity. Global and Planetary Change, 115, 44-58. https://doi.org/10.1016/j.gloplacha.2014.01.011

Cohen, S., Kettner, A. J., Syvitski, J. P. M., \& Fekete, B. M. (2013). WBMsed, a distributed global-scale riverine sediment flux model: Model description and validation. Computers and Geosciences, 53, 80-93. https://doi.org/10.1016/j.cageo.2011.08.011

Crosato, A., \& Mosselman, E. (2009). Simple physics-based predictor for the number of river bars and the transition between meandering and braiding. Water Resources Research, 45(3). https://doi.org/10.1029/2008WR007242 
https://doi.org/10.5194/hess-2021-491

Preprint. Discussion started: 30 September 2021

(c) Author(s) 2021. CC BY 4.0 License.

Hydrology and

Earth System

Sciences

Discussions

Crosato, A., Mosselman, E., Beidmariam Desta, F., \& Uijttewaal, W. S. J. (2011). Experimental and numerical evidence for intrinsic nonmigrating bars in alluvial channels. Water Resources Research, 47(3). https://doi.org/10.1029/2010WR009714

Czuba, J. A., Foufoula-Georgiou, E., Gran, K. B., Belmont, P., \& Wilcock, P. R. (2017). Interplay between spatially explicit sediment sourcing, hierarchical river-network structure, and in-channel bed material sediment transport and storage dynamics. Journal of Geophysical Research: Earth Surface, 122(5). https://doi.org/10.1002/2016JF003965

Darby, S. E., Alabyan, A. M., \& Van de Wiel, M. J. (2002). Numerical simulation of bank erosion and channel migration in meandering rivers. Water Resources Research, 38(9). https://doi.org/10.1029/2001wr000602

Einstein, H. A., Anderson, A. G., \& Johnson, J. W. (1940). A distinction between bed-load and suspended load in natural streams. Eos, Transactions American Geophysical Union, 21(2). https://doi.org/10.1029/TR021i002p00628

Engelund, F., \& Hansen, E. (1967). A monograph on sediment transport in alluvial streams. Monografia.

Fang, H. W., Lai, H. J., Cheng, W., Huang, L., \& He, G. J. (2017). Modeling sediment transport with an integrated view of the biofilm effects. Water Resources Research, 53(9). https://doi.org/10.1002/2017WR020628

Ferguson, R. I., Church, M., Rennie, C. D., \& Venditti, J. G. (2015). Reconstructing a sediment pulse: Modeling the effect of placer mining on Fraser River, Canada. Journal of Geophysical Research F: Earth Surface, 120(7). https://doi.org/10.1002/2015JF003491

Garcia (Ed.), M. H. (2008). Sedimentation Engineering: Processes, Measurements, Modeling, and Practice. In M. H. Garcia (Ed.), American Society of Civil Engineers. American Society of Civil Engineers.

Geleynse, N., Storms, J. E. A., Walstra, D. J. R., Jagers, H. R. A., Wang, Z. B., \& Stive, M. J. F. (2011). Controls on river delta formation; insights from numerical modelling. Earth and Planetary Science Letters, 302(1-2). https://doi.org/10.1016/j.epsl.2010.12.013

Getirana, A., Dutra, E., Guimberteau, M., Kam, J., Li, H. Y., Decharme, B., Zhang, Z., Ducharne, A., Boone, A., Balsamo, G., Rodell, M., Toure, A. M., Xue, Y., Peters-Lidard, C. D., Kumar, S. V., Arsenault, K., Drapeau, G., Leung, L. R., Ronchail, J., \& Sheffield, J. (2014). Water balance in the amazon basin from a land surface model ensemble. Journal of Hydrometeorology, 15(6), 2586-2614. https://doi.org/10.1175/JHM-D-14-0068.1

Getirana, A., Kumar, S. V., Konapala, G., \& Ndehedehe, C. E. (2021). Impacts of Fully Coupling Land Surface and Flood Models on the Simulation of Large Wetlands' Water Dynamics: The Case of the Inner Niger Delta. Journal of Advances in Modeling Earth Systems, 13(5). https://doi.org/10.1029/2021MS002463

Golaz, J. C., Caldwell, P. M., Van Roekel, L. P., Petersen, M. R., Tang, Q., Wolfe, J. D., Abeshu, G., Anantharaj, V., AsayDavis, X. S., Bader, D. C., Baldwin, S. A., Bisht, G., Bogenschutz, P. A., Branstetter, M., Brunke, M. A., Brus, S. R., Burrows, S. M., Cameron-Smith, P. J., Donahue, A. S., ... Zhu, Q. (2019). The DOE E3SM Coupled Model Version 1: Overview and Evaluation at Standard Resolution. Journal of Advances in Modeling Earth Systems, 11(7), 2089-2129. https://doi.org/10.1029/2018MS001603

Greimann, B., Lai, Y., \& Huang, J. (2008). Two-Dimensional Total Sediment Load Model Equations. Journal of Hydraulic Engineering, 134(8), 1142-1146. https://doi.org/10.1061/(asce)0733-9429(2008)134:8(1142)

Groten, J. T., \& Johnson, G. D. (2018). Comparability of River SuspendedSediment Sampling and Laboratory Analysis Methods.

Gupta, H. V., Kling, H., Yilmaz, K. K., \& Martinez, G. F. (2009). Decomposition of the mean squared error and NSE performance criteria: Implications for improving hydrological modelling. Journal of Hydrology, 377(1-2). https://doi.org/10.1016/j.jhydrol.2009.08.003

Holeman, J. N. (1968). The Sediment Yield of Major Rivers of the World. Water Resources Research, 4(4). https://doi.org/10.1029/WR004i004p00737 
https://doi.org/10.5194/hess-2021-491

Preprint. Discussion started: 30 September 2021

(c) Author(s) 2021. CC BY 4.0 License.

Hydrology and

Earth System

Sciences

Discussions

Holly, F. M., \& Rahuel, J.-L. (1990). New numerical/physical framework for mobile-bed modelling. Journal of Hydraulic Research, 28(4). https://doi.org/10.1080/00221689009499057

Kirwan, M. L., \& Megonigal, J. P. (2013). Tidal wetland stability in the face of human impacts and sea-level rise. In Nature (Vol. 504, Issue 7478). https://doi.org/10.1038/nature12856

760

765

Kleinhans, M. G., Jagers, H. R. A., Mosselman, E., \& Sloff, C. J. (2008). Bifurcation dynamics and avulsion duration in meandering rivers by one-dimensional and three-dimensional models. Water Resources Research, 44(8). https://doi.org/10.1029/2007WR005912

Knoben, W. J. M., Freer, J. E., \& Woods, R. A. (2019). Technical note: Inherent benchmark or not? Comparing Nash-Sutcliffe and Kling-Gupta efficiency scores. Hydrology and Earth System Sciences, 23(10). https://doi.org/10.5194/hess-23-43232019

Lal, R. (2003). Soil erosion and the global carbon budget. In Environment International (Vol. 29, Issue 4). https://doi.org/10.1016/S0160-4120(02)00192-7

Lal, R. (2004). Soil carbon sequestration impacts on global climate change and food security. In Science (Vol. 304, Issue 5677). https://doi.org/10.1126/science.1097396

Lamb, M. P., \& Venditti, J. G. (2016). The grain size gap and abrupt gravel-sand transitions in rivers due to suspension fallout. Geophysical Research Letters, 43(8), 3777-3785. https://doi.org/10.1002/2016GL068713

Lane, E. W. (1947). Report of the Subcommittee on Sediment Terminology. Eos, Transactions American Geophysical Union, 28(6). https://doi.org/10.1029/TR028i006p00936

Lawrence, D. M., Fisher, R. A., Koven, C. D., Oleson, K. W., Swenson, S. C., Bonan, G., Collier, N., Ghimire, B., Kampenhout, L., Kennedy, D., Kluzek, E., Lawrence, P. J., Li, F., Li, H., Lombardozzi, D., Riley, W. J., Sacks, W. J., Shi, M., Vertenstein, M., ... Zeng, X. (2019). The Community Land Model version 5: Description of new features, benchmarking, and impact of forcing uncertainty. Journal of Advances in Modeling Earth Systems, 2, 1-43. https://doi.org/10.1029/2018ms001583

Lee, H.-Y., Hsieh, H.-M., Yang, J.-C., \& Yang, C. T. (1997). Quasi-Two-Dimensional Simulation of Scour and Deposition in Alluvial Channels. Journal of Hydraulic Engineering, 123(7). https://doi.org/10.1061/(asce)07339429(1997)123:7(600)

Lehner, B., Liermann, C. R., Revenga, C., Vörömsmarty, C., Fekete, B., Crouzet, P., Döll, P., Endejan, M., Frenken, K., Magome, J., Nilsson, C., Robertson, J. C., Rödel, R., Sindorf, N., \& Wisser, D. (2011). High-resolution mapping of the world's reservoirs and dams for sustainable river-flow management. In Frontiers in Ecology and the Environment (Vol. 9, Issue 9). https://doi.org/10.1890/100125

Lewis, S. E., Bainbridge, Z. T., Kuhnert, P. M., Sherman, B. S., Henderson, B., Dougall, C., Cooper, M., \& Brodie, J. E. (2013). Calculating sediment trapping efficiencies for reservoirs in tropical settings: A case study from the Burdekin Falls Dam, NE Australia. Water Resources Research, 49(2), 1017-1029. https://doi.org/10.1002/wrcr.20117

Li, H.-Y., Leung, L. R., Getirana, A., Huang, M., Wu, H., Xu, Y., Guo, J., \& Voisin, N. (2015). Evaluating global streamflow simulations by a physically based routing model coupled with the community land model. Journal of Hydrometeorology, 16(2), 948-971. https://doi.org/10.1175/JHM-D-14-0079.1

Li, H.-Y., Leung, R. L., Tesfa, T., Voisin, N., Hejazi, M., Liu, L., Liu, Y., Rice, J., Wu, H., \& Yang, X. (2015). Modeling stream temperature in the Anthropocene: An earth system modeling approach. Journal of Advances in Modeling Earth Systems, 7(4), 1661-1679. https://doi.org/10.1002/2015MS000471

Li, H.-Y., Wigmosta, M. S., Wu, H., Huang, M., Ke, Y., Coleman, A. M., \& Leung, L. R. (2013). A physically based runoff routing model for land surface and earth system models. Journal of Hydrometeorology, 14(3), 808-828.

Ludwig, W., \& Probst, J. L. (1996). A global modelling of the climatic, morphological, and lithological control of river sediment discharges to the oceans. IAHS-AISH Publication, 236(236), 21-28. 
https://doi.org/10.5194/hess-2021-491

Preprint. Discussion started: 30 September 2021

(C) Author(s) 2021. CC BY 4.0 License.
Hydrology and

Earth System

Sciences

Discussions
800

Luo, X., Li, H. Y., Ruby Leung, L., Tesfa, T. K., Getirana, A., Papa, F., \& Hess, L. L. (2017). Modeling surface water dynamics in the Amazon Basin using MOSART-Inundation v1.0: Impacts of geomorphological parameters and river flow representation. Geoscientific Model Development, 10(3). https://doi.org/10.5194/gmd-10-1233-2017

Ma, H., Nittrouer, J. A., Naito, K., Fu, X., Zhang, Y., Moodie, A. J., Wang, Y., Wu, B., \& Parker, G. (2017). The exceptional sediment load of fine-grained dispersal systems: Example of the Yellow River, China. Science Advances, 3(5). https://doi.org/10.1126/sciadv.1603114

Ma, H., Nittrouer, J. A., Wu, B., Lamb, M. P., Zhang, Y., Mohrig, D., Fu, X., Naito, K., Wang, Y., Moodie, A. J., Wang, G., Hu, C., \& Parker, G. (2020). Universal relation with regime transition for sediment transport in fine-grained rivers. Proceedings of the National Academy of Sciences of the United States of America, 117(1). https://doi.org/10.1073/pnas.1911225116

Maavara, T., Chen, Q., Van Meter, K., Brown, L. E., Zhang, J., Ni, J., \& Zarfl, C. (2020). River dam impacts on biogeochemical cycling. In Nature Reviews Earth and Environment (Vol. 1, Issue 2). https://doi.org/10.1038/s43017-019-0019-0

Manning, R. (1891). On the flow of water in open channels and pipes. Trans. Inst. Civil Eng. Ireland, 20.

McKay, L., Bondelid, T., Dewald, T., Johnston, J., Moore, R., and Rea, A. (2012). NHDPlus Version 2: User Guide.

Meade, R. H., \& Milliman, J. D. (1983). World-Wide Delivery of River Sediment to the Oceans. Journal of Geology, 91(1).

Meade, R. H., \& Moody, J. A. (2010). Causes for the decline of suspended-sediment discharge in the Mississippi River system, 1940-2007. Hydrological Processes, 24(1). https://doi.org/10.1002/hyp.7477

Mitchell, K. E., Lohmann, D., Houser, P. R., Wood, E. F., Schaake, J. C., Robock, A., Cosgrove, B. A., Sheffield, J., Duan, Q., Luo, L., Higgins, R. W., Pinker, R. T., Tarpley, J. D., Lettenmaier, D. P., Marshall, C. H., Entin, J. K., Pan, M., Shi, W., Koren, V., ... Bailey, A. A. (2004). The multi-institution North American Land Data Assimilation System (NLDAS): Utilizing multiple GCIP products and partners in a continental distributed hydrological modeling system. Journal of Geophysical Research: Atmospheres, 109(7). https://doi.org/10.1029/2003jd003823

Mizukami, N., Clark, M. P., Gharari, S., Kluzek, E., Pan, M., Lin, P., Beck, H. E., \& Yamazaki, D. (2021). A Vector-Based River Routing Model for Earth System Models: Parallelization and Global Applications. Journal of Advances in Modeling Earth Systems, 13(6). https://doi.org/10.1029/2020MS002434

Moodie, A. J., Nittrouer, J. A., Ma, H., Carlson, B. N., Wang, Y., Lamb, M. P., \& Parker, G. (2020). Suspended-sediment induced stratification inferred from concentration and velocity profile measurements in the lower Yellow River, China. Water Resources Research. https://doi.org/10.1029/2020wr027192

Moragoda, N., \& Cohen, S. (2020). Climate-induced trends in global riverine water discharge and suspended sediment dynamics in the 21st century. Global and Planetary Change, 191. https://doi.org/10.1016/j.gloplacha.2020.103199

Morgan, R. P. C. (2001). A simple approach to soil loss prediction: A revised Morgan-Morgan-Finney model. Catena, 44(4). https://doi.org/10.1016/S0341-8162(00)00171-5

Morgan, R. P. C., \& Duzant, J. H. (2008). Modified MMF (Morgan-Morgan-Finney) model for evaluating effects of crops and vegetation cover on soil erosion. Earth Surface Processes and Landforms, 33(1). https://doi.org/10.1002/esp.1530

Mosselman, E. (1998). Morphological modelling of rivers with erodible banks. Hydrological Processes, 12(8). https://doi.org/10.1002/(SICI)1099-1085(19980630)12:8<1357::AID-HYP619>3.0.CO;2-7

Naito, K., Ma, H., Nittrouer, J. A., Zhang, Y., Wu, B., Wang, Y., Fu, X., \& Parker, G. (2019). Extended Engelund-Hansen type sediment transport relation for mixtures based on the sand-silt-bed Lower Yellow River, China. Journal of Hydraulic Research, 57(6). https://doi.org/10.1080/00221686.2018.1555554

Nicholas, A. P. (2013). Modelling the continuum of river channel patterns. In Earth Surface Processes and Landforms (Vol. 38, Issue 10). https://doi.org/10.1002/esp.3431

Nienhuis, J. H., Ashton, A. D., Edmonds, D. A., Hoitink, A. J. F., Kettner, A. J., Rowland, J. C., \& Törnqvist, T. E. (2020). 
https://doi.org/10.5194/hess-2021-491

Preprint. Discussion started: 30 September 2021

(c) Author(s) 2021. CC BY 4.0 License.

Hydrology and

Earth System

Sciences

Discussions

Global-scale human impact on delta morphology has led to net land area gain. Nature, 577(7791). https://doi.org/10.1038/s41586-019-1905-9

Nilsson, C., Reidy, C. A., Dynesius, M., \& Revenga, C. (2005). Fragmentation and flow regulation of the world's large river systems. In Science (Vol. 308, Issue 5720). https://doi.org/10.1126/science.1107887

Nittrouer, J. A., Shaw, J., Lamb, M. P., \& Mohrig, D. (2012). Spatial and temporal trends for water-flow velocity and bedmaterial sediment transport in the lower Mississippi River. Bulletin of the Geological Society of America, 124(3-4). https://doi.org/10.1130/B30497.1

Nittrouer, J. A., \& Viparelli, E. (2014). Sand as a stable and sustainable resource for nourishing the Mississippi River delta. Nature Geoscience, 7(5). https://doi.org/10.1038/ngeo2142

Patil, S., Sivapalan, M., Hassan, M. A., Ye, S., Harman, C. J., \& Xu, X. (2012). A network model for prediction and diagnosis of sediment dynamics at the watershed scale. Journal of Geophysical Research F: Earth Surface, 117(4), 1-17. https://doi.org/10.1029/2012JF002400

Pelletier, J. D. (2012). A spatially distributed model for the long-term suspended sediment discharge and delivery ratio of drainage basins. Journal of Geophysical Research: Earth Surface, 117(2). https://doi.org/10.1029/2011JF002129

Rijn, L. C. van. (1989). Handbook Sediment Transport by Currents and Wave. Delft Hydraulics.

Rousseau, Y. Y., Biron, P. M., \& Van de Wiel, M. J. (2016). Sensitivity of simulated flow fields and bathymetries in meandering channels to the choice of a morphodynamic model. Earth Surface Processes and Landforms, 41(9). https://doi.org/10.1002/esp.3885

Sadeghi, S. H., \& Singh, V. P. (2017). Dynamics of suspended sediment concentration, flow discharge and sediment particle size interdependency to identify sediment source. Journal of Hydrology, 554. https://doi.org/10.1016/j.jhydrol.2017.09.006

Schmitt, R. J. P., Bizzi, S., \& Castelletti, A. (2016). Tracking multiple sediment cascades at the river network scale identifies controls and emerging patterns of sediment connectivity. Water Resources Research, 52(5). https://doi.org/10.1002/2015WR018097

Schmitt, R. J. P., Bizzi, S., Castelletti, A., \& Kondolf, G. M. (2018). Improved trade-offs of hydropower and sand connectivity by strategic dam planning in the Mekong. Nature Sustainability, l(2). https://doi.org/10.1038/s41893-018-0022-3

Schuurman, F., Marra, W. A., \& Kleinhans, M. G. (2013). Physics-based modeling of large braided sand-bed rivers: Bar pattern formation, dynamics, and sensitivity. Journal of Geophysical Research: Earth Surface, 118(4). https://doi.org/10.1002/2013JF002896

Schwarz, G. E., Jackson, S. E., \& Wieczorek, M. E. (2018). Select Attributes for NHDPlus Version 2.1 Reach Catchments and Modified Network Routed Upstream Watersheds for the Conterminous United States. United States Geological Survey.

Simon, A., \& Darby, S. E. (1997). Process-form interactions in unstable sand-bed river channels: A numerical modeling approach. Geomorphology, 21(2). https://doi.org/10.1016/S0169-555X(97)00043-3

Su, C. C., Lu, J. Y., \& Hong, J. H. (2013). A field investigation of the sediment transport characteristics of a high sediment load intermittent river in Taiwan. Hydrological Processes, 27(26). https://doi.org/10.1002/hyp.9517

Sun, J., Lin, B., \& Yang, H. (2015). Development and application of a braided river model with non-uniform sediment transport. Advances in Water Resources, 81. https://doi.org/10.1016/j.advwatres.2014.12.012

Syvitski, J. P. M., Peckham, S. D., Hilberman, R., \& Mulder, T. (2003). Predicting the terrestrial flux of sediment to the global ocean: A planetary perspective. Sedimentary Geology, 162(1-2), 5-24. https://doi.org/10.1016/S0037-0738(03)00232$\mathrm{X}$

Syvitski, J. P. M., Vörösmarty, C. J., Kettner, A. J., \& Green, P. (2005). Impact of humans on the flux of terrestrial sediment to the global coastal ocean. Science, 308(5720), 376-380. https://doi.org/10.1126/science.1109454 
https://doi.org/10.5194/hess-2021-491

Preprint. Discussion started: 30 September 2021

(c) Author(s) 2021. CC BY 4.0 License.

Hydrology and

Earth System

Sciences

Discussions

Tan, Z., Leung, L. R., Li, H.-Y., \& Tesfa, T. (2018). Modeling sediment yield in land surface and Earth system models: Model comparison, development, and evaluation. Journal of Advances in Modeling Earth Systems, 10(9), 2192-2213.

Tan, Z., Leung, L. R., Li, H. Y., Tesfa, T., Zhu, Q., Yang, X., Liu, Y., \& Huang, M. (2021). Increased extreme rains intensify erosional nitrogen and phosphorus fluxes to the northern Gulf of Mexico in recent decades. Environmental Research Letters, 16(5). https://doi.org/10.1088/1748-9326/abf006

Tan, Z., Leung, R. L., Li, H.-Y., Tesfa, T., Zhu, Q., \& Huang, M. (2020). A substantial role of soil erosion in the land carbon sink and its future changes. Global Change Biology, 26(4). https://doi.org/10.1111/gcb.14982

Tsuruta, K., Hassan, M. A., Donner, S. D., \& Alila, Y. (2018). Development and Application of a Large-Scale, Physically Based, Distributed Suspended Sediment Transport Model on the Fraser River Basin, British Columbia, Canada. Journal of Geophysical Research: Earth Surface, 123(10), 2481-2508. https://doi.org/10.1029/2017JF004578

Van Der Wegen, M., \& Roelvink, J. A. (2008). Long-term morphodynamic evolution of a tidal embayment using a twodimensional, process-based model. Journal of Geophysical Research: Oceans, 113(3). https://doi.org/10.1029/2006JC003983

Van Oost, K., Quine, T. A., Govers, G., De Gryze, S., Six, J., Harden, J. W., Ritchie, J. C., McCarty, G. W., Heckrath, G., Kosmas, C., Giraldez, J. V., Marques Da Silva, J. R., \& Merckx, R. (2007). The impact of agricultural soil erosion on the global carbon cycle. Science, 318(5850). https://doi.org/10.1126/science.1145724

Voisin, N., Li, H., Ward, D., Huang, M., Wigmosta, M., \& Leung, L. R. (2013). On an improved sub-regional water resources management representation for integration into earth system models. Hydrology and Earth System Sciences, 17(9), 3605-3622.

Voisin, N., Liu, L., Hejazi, M., Tesfa, T., Li, H., Huang, M., Liu, Y., \& Leung, L. R. (2013). One-way coupling of an integrated assessment model and a water resources model: evaluation and implications of future changes over the US Midwest. Hydrology and Earth System Sciences, 17(11), 4555-4575.

Vörösmarty, C. J., Meybeck, M., Fekete, B., Sharma, K., Green, P., \& Syvitski, J. P. M. (2003). Anthropogenic sediment retention: Major global impact from registered river impoundments. Global and Planetary Change, 39(1-2), 169-190. https://doi.org/10.1016/S0921-8181(03)00023-7

Wang, W., Li, H.-Y., Leung, L. R., Yigzaw, W., Zhao, J., Lu, H., Deng, Z., Demisie, Y., \& Blöschl, G. (2017). Nonlinear Filtering Effects of Reservoirs on Flood Frequency Curves at the Regional Scale. Water Resources Research, 53(10). https://doi.org/10.1002/2017WR020871

White, M. J., Santhi, C., Kannan, N., Arnold, J. G., Harmel, D., Norfleet, L., Allen, P., DiLuzio, M., Wang, X., Atwood, J., Haney, E., \& Johnson, M. V. (2014). Nutrient delivery from the Mississippi River to the Gulf of Mexico and effects of cropland conservation. Journal of Soil and Water Conservation, 69(1). https://doi.org/10.2489/jswc.69.1.26

Wiele, S. M., Graf, J. B., \& Smith, J. D. (1996). Sand deposition in the Colorado River in the Grand Canyon from flooding of the Little Colorado River. Water Resources Research, 32(12). https://doi.org/10.1029/96WR02842

Wise, D. R., III, F. A. R., Rinella, J. F., Fuhrer, G. J., Clark, S. S. E. G. M., Schwarz, G. E., \& Sobieszczyk, S. (2007). Nutrient and Suspended-Sediment Transport and Trends in the Columbia River and Puget Sound Basins, 1993-2003. https://pubs.usgs.gov/sir/2007/5186/

Wu, H., Kimball, J. S., Li, H.-Y., Huang, M., Leung, L. R., \& Adler, R. F. (2012). A new global river network database for macroscale hydrologic modeling. Water Resources Research, 48(9). https://doi.org/10.1029/2012WR012313

Wu, H., Kimball, J. S., Mantua, N., \& Stanford, J. (2011). Automated upscaling of river networks for macroscale hydrological modeling. Water Resources Research, 47(3). https://doi.org/10.1029/2009WR008871

Wu, W., Shields, F. D., Bennett, S. J., \& Wang, S. S. Y. (2005). A depth-averaged two-dimensional model for flow, sediment transport, and bed topography in curved channels with riparian vegetation. Water Resources Research, 41(3). https://doi.org/10.1029/2004WR003730 
https://doi.org/10.5194/hess-2021-491

Preprint. Discussion started: 30 September 2021

(C) Author(s) 2021. CC BY 4.0 License.

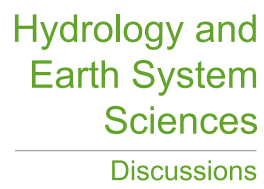

(c) (1)

Discussions

Wu, W., Wang, S. S. Y., \& Jia, Y. (2000). Nonuniform sediment transport in alluvial rivers. Journal of Hydraulic Research, 38(6). https://doi.org/10.1080/00221680009498296

Zhang, R., \& Xie, J. (1993). Sedimentation Research in China: Systematic Selections. China Water and Power Press.

930

935

940

945

950

955 


\section{List of Tables}

Table 1. List of selected USGS gauges and model performance

\begin{tabular}{|c|c|c|c|c|c|c|c|c|c|c|}
\hline \multirow{3}{*}{ USGS ID } & \multirow{3}{*}{$\begin{array}{c}\text { Area } \\
\left(\mathbf{k m}^{2}\right)\end{array}$} & \multirow{3}{*}{$\begin{array}{c}\text { Number of } \\
\text { months with } \\
\text { observations }\end{array}$} & \multicolumn{4}{|c|}{ Sim_nat } & \multicolumn{4}{|c|}{ Sim_wm_trapping } \\
\hline & & & \multicolumn{2}{|c|}{ Streamflow } & \multicolumn{2}{|c|}{$\begin{array}{c}\text { Suspended } \\
\text { sediment }\end{array}$} & \multicolumn{2}{|c|}{ Streamflow } & \multicolumn{2}{|c|}{$\begin{array}{c}\text { Suspended } \\
\text { sediment }\end{array}$} \\
\hline & & & KGE & NRMSEI & KGE & NRMSE & KGE & NRMSE & KGE & NRMSE \\
\hline 07022000 & 1850000 & 276 & 0.79 & 0.36 & -0.22 & 1.73 & 0.81 & 0.26 & 0.45 & 1.06 \\
\hline 07020500 & 1840000 & 275 & 0.79 & 0.35 & 0.06 & 1.48 & 0.82 & 0.25 & 0.46 & 1.00 \\
\hline 07010000 & 1810000 & 275 & 0.80 & 0.34 & 0.05 & 1.53 & 0.82 & 0.24 & 0.47 & 1.03 \\
\hline 06807000 & 1060000 & 255 & -0.20 & 0.98 & -0.98 & 2.48 & 0.36 & 0.64 & 0.62 & 0.88 \\
\hline 06610000 & 836000 & 194 & 0.16 & 0.80 & -0.97 & 2.32 & 0.19 & 0.68 & 0.50 & 0.84 \\
\hline 06486000 & 815000 & 218 & 0.00 & 1.04 & -5.46 & 7.30 & 0.11 & 0.83 & -0.92 & 2.43 \\
\hline 05587455 & 444000 & 183 & 0.77 & 0.33 & -1.44 & 2.83 & 0.71 & 0.34 & -0.69 & 2.12 \\
\hline 05389500 & 175000 & 176 & 0.82 & 0.34 & -18.46 & 19.09 & 0.76 & 0.35 & -14.83 & 15.61 \\
\hline 05586100 & 69264 & 260 & 0.69 & 0.41 & 0.28 & 1.18 & 0.64 & 0.44 & 0.35 & 0.99 \\
\hline 05288500 & 49469 & 80 & 0.74 & 0.40 & -5.27 & 7.30 & 0.64 & 0.38 & -3.51 & 5.42 \\
\hline 05325000 & 38591 & 276 & 0.64 & 0.63 & 0.58 & 1.40 & 0.55 & 0.68 & 0.54 & 1.23 \\
\hline 05465500 & 32375 & 224 & 0.85 & 0.39 & 0.29 & 1.58 & 0.81 & 0.40 & 0.52 & 1.30 \\
\hline 06452000 & 25680 & 276 & 0.41 & 1.24 & -0.36 & 1.78 & 0.51 & 1.14 & -0.34 & 1.77 \\
\hline 05543500 & 21391 & 79 & 0.44 & 0.57 & 0.25 & 1.52 & 0.39 & 0.61 & 0.46 & 1.21 \\
\hline 04193500 & 16395 & 164 & 0.36 & 0.77 & -0.33 & 1.51 & 0.35 & 0.77 & -0.35 & 1.52 \\
\hline 12340500 & 15594 & 269 & 0.66 & 0.73 & -24.85 & 47.98 & 0.71 & 0.68 & -22.33 & 43.86 \\
\hline 05481650 & 15128 & 176 & 0.60 & 0.67 & -2.92 & 6.25 & 0.57 & 0.68 & -2.25 & 5.21 \\
\hline 06918070 & 14012 & 96 & 0.58 & 0.73 & -0.44 & 1.87 & 0.50 & 0.78 & 0.07 & 1.39 \\
\hline 05594100 & 11378 & 92 & 0.69 & 0.62 & -0.04 & 1.49 & 0.59 & 0.66 & 0.58 & 0.97 \\
\hline 05474000 & 11168 & 276 & 0.69 & 0.81 & 0.00 & 1.68 & 0.69 & 0.78 & 0.01 & 1.67 \\
\hline 01331095 & 9772 & 135 & 0.62 & 0.51 & -541.42 & 773.46 & 0.56 & 0.40 & -232.26 & 284.84 \\
\hline 12334550 & 9472 & 272 & 0.03 & 1.11 & -9.73 & 18.44 & 0.15 & 0.99 & -6.91 & 14.03 \\
\hline 01357500 & 8936 & 99 & 0.82 & 0.39 & -39.38 & 44.14 & 0.75 & 0.39 & -33.69 & 37.95 \\
\hline 05552500 & 6843 & 78 & 0.66 & 0.63 & 0.21 & 1.85 & 0.67 & 0.61 & 0.27 & 1.78 \\
\hline 12340000 & 5923 & 156 & 0.47 & 1.02 & 0.26 & 2.62 & 0.48 & 1.01 & 0.28 & 2.61 \\
\hline 05599500 & 5618 & 92 & 0.37 & 1.15 & -1.92 & 3.53 & 0.38 & 0.92 & -0.25 & 1.81 \\
\hline 05570000 & 4237 & 153 & 0.63 & 0.75 & 0.17 & 1.49 & 0.63 & 0.73 & 0.15 & 1.49 \\
\hline 06921760 & 3289 & 96 & 0.51 & 1.02 & 0.03 & 1.91 & 0.49 & 1.03 & 0.33 & 1.60 \\
\hline 04198000 & 3240 & 152 & 0.37 & 0.82 & -0.26 & 1.40 & 0.37 & 0.82 & -0.26 & 1.40 \\
\hline 04208000 & 1831 & 152 & 0.43 & 0.55 & -0.09 & 1.18 & 0.33 & 0.61 & -0.25 & 1.28 \\
\hline 07036100 & 1720 & 80 & 0.29 & 0.91 & 0.28 & 1.53 & 0.29 & 0.91 & 0.28 & 1.53 \\
\hline 05532500 & 1632 & 120 & 0.77 & 0.46 & -0.31 & 1.71 & 0.67 & 0.51 & -0.30 & 1.71 \\
\hline
\end{tabular}


https://doi.org/10.5194/hess-2021-491

Preprint. Discussion started: 30 September 2021

(c) Author(s) 2021. CC BY 4.0 License.

\begin{tabular}{|l|r|r|r|r|r|r|r|r|r|r|}
03230500 & 1383 & 69 & 0.33 & 0.75 & -0.31 & 2.32 & -0.04 & 0.95 & 0.33 & 1.36 \\
\hline 14242580 & 1285 & 275 & 0.80 & 0.32 & -0.38 & 2.73 & 0.84 & 0.33 & -0.43 & 2.78 \\
\hline 05591200 & 1225 & 92 & 0.50 & 0.88 & -0.16 & 2.09 & 0.51 & 0.87 & -0.16 & 2.09 \\
\hline
\end{tabular}

965 


\section{List of Figures}

995 Fig. 1 Modeling framework of MOSART-sediment.

Fig. 2 Important parameters over the study domain.

Fig. 3 a. River network displayed using upstream drainage area and 35 selected USGS gauges (black stars) and 3 representative gauges (red stars) along the river networks (approximated). b. change of local channel water residence time due to reservoirs. Fig. 4 Spatial maps of simulated streamflow, total suspended load, wash load and suspended bed-material load averaged in 1990-2012.

Fig. 5 Simulated versus observed annual mean discharge of water and total suspended load in 1990-2012. Each dot represents one USGS gauge.

Fig. 6 Evaluation of simulated monthly streamflow and suspended sediment at the selected USGS stations in 1990-2012. The river network is displayed as a background in terms of the accumulated upstream drainage areas at each grid (in different tones of blue).

Fig. 7 Comparison of model structure in terms of KGE and NRMSE between the simulated and observed monthly time series at different USGS gauges. EH and Wu stand for the Engelund-Hansen and Wu's formulas respectively. DW and KW stand for the diffusion and kinematic wave routing methods respectively.

Fig. 8 Simulated and observed monthly streamflow and suspended sediment discharge at three USGS gauges representative of different levels of flow regulation. For clarity, only the sim_nat and sim_wm_trapping results are displayed here.

Fig. 9 Change of KGE from sim_nat to sim_wm_trapping for monthly streamflow and suspended sediment at the selected USGS stations in 1990-2012. The river network is displayed as a background in terms of the accumulated upstream drainage areas at each grid (in different tones of blue).

Fig. 10 Simulated and observed mean monthly streamflow (left) and suspended sediment discharge (right) at three USGS 1015 gauges representative of different levels of flow regulation.

Fig. 11 Spatial patterns of sensitivity of median bed-material size (d50) (a, b), channel slope ( $r s l p)$ (c, d), and Manning's roughness for channels $(n r)(\mathrm{e}, \mathrm{f})$. At each grid, the percentage change of suspended load is calculated as $100 \% *\left(\mathrm{~S}_{1}-\mathrm{S}_{0}\right) / \mathrm{S}_{0}$, where $S_{1}$ and $S_{0}$ are the average suspended load 1990-2012 simulated with the parameter changing by $10 \%$, and the average suspended load simulated with the original parameters, respectively.

1020 Fig. 12 Boxplot of the changes in total suspended load when changing the parameters.

Fig. 13 Impacts of reservoirs on (a) streamflow and (b) wash load to the coasts. Each dot in Figure 13 represents the lat/lon grid at the river mouth of a river system. The larger the dot size, the larger the freshwater or suspended sediment discharge simulated with Sim_wm_trapping. The color of each dot represents the percentage of freshwater or suspended sediment discharge that is reduced by water management or reservoirs, i.e., (sim_nat-Sim_wm_trapping $) / s i m \_n a t$. 
https://doi.org/10.5194/hess-2021-491

Preprint. Discussion started: 30 September 2021

(c) Author(s) 2021. CC BY 4.0 License.
Hydrology and Earth System Sciences Discussions

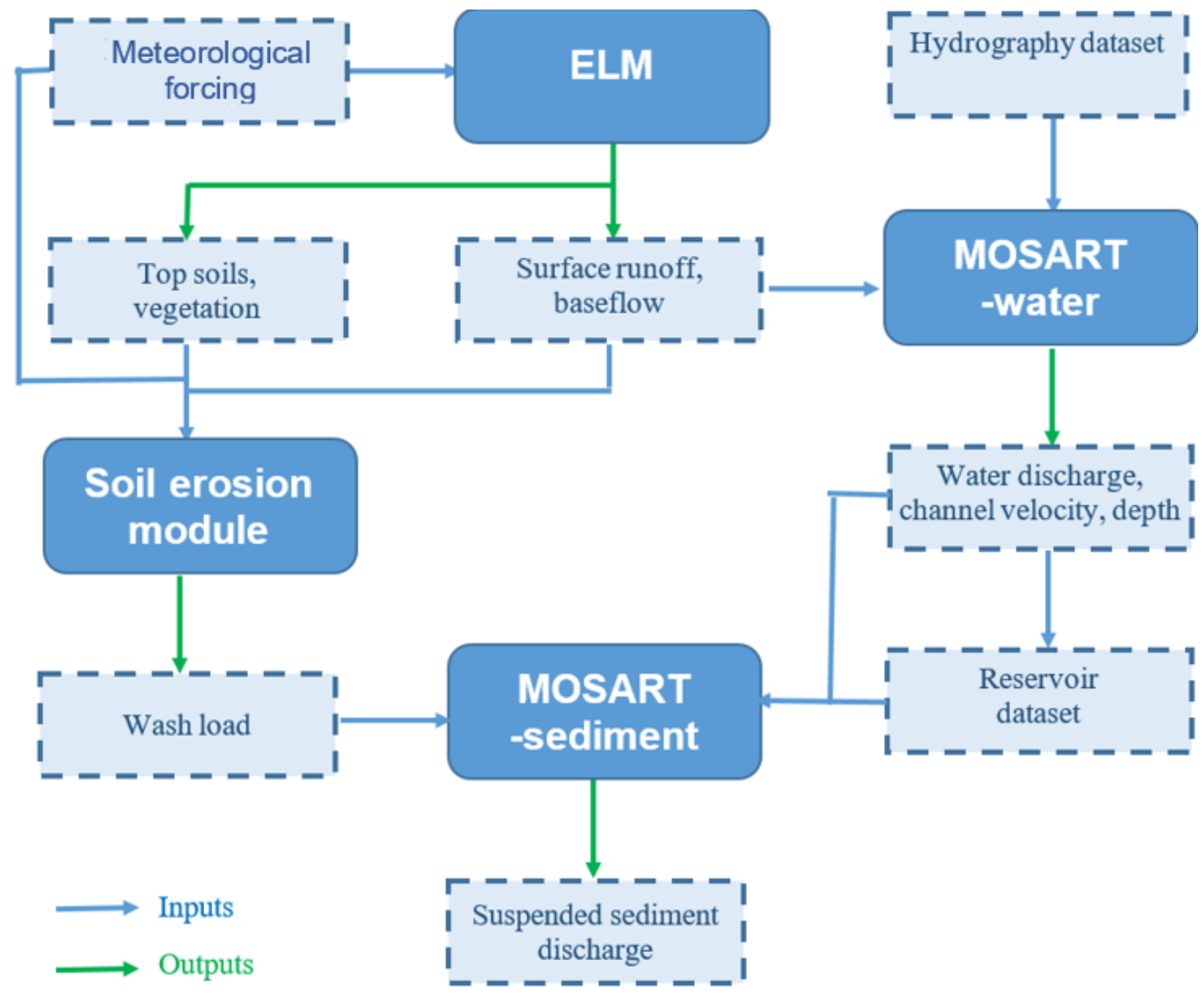

1030 Figure 1: Modeling framework of MOSART-sediment. 
https://doi.org/10.5194/hess-2021-491

Preprint. Discussion started: 30 September 2021

(c) Author(s) 2021. CC BY 4.0 License.

(c) (1) a) Median bed-material particle size
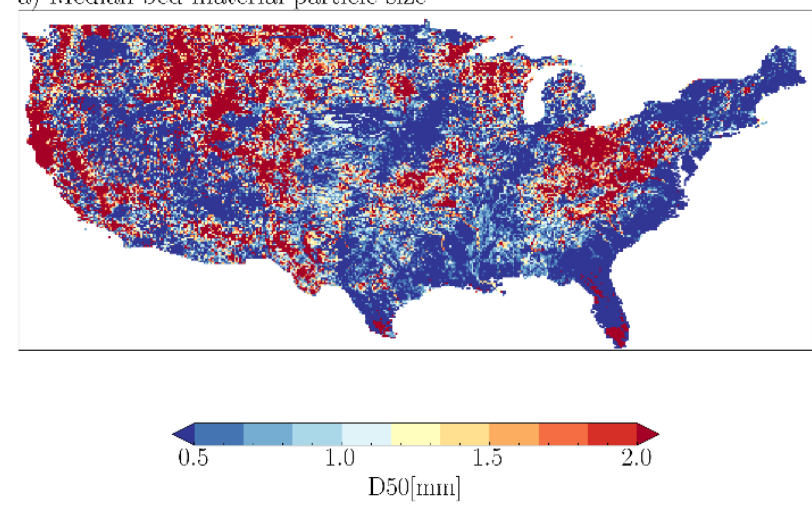

c) Bankfull depth of main channel
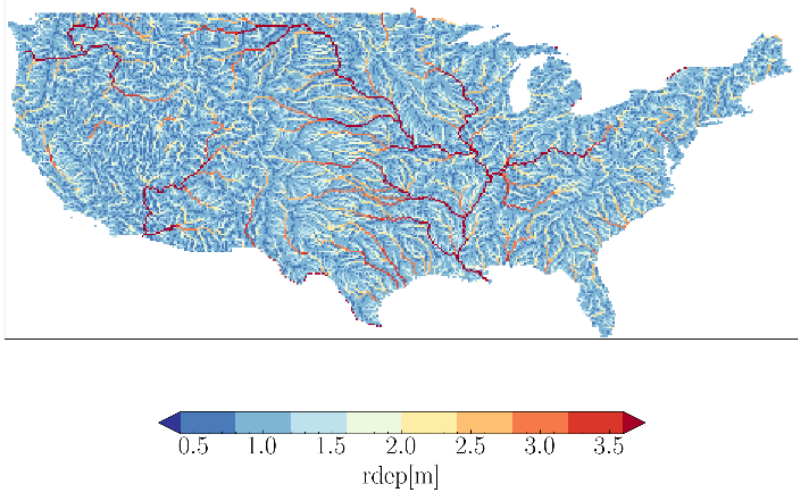

c) Main channel slope
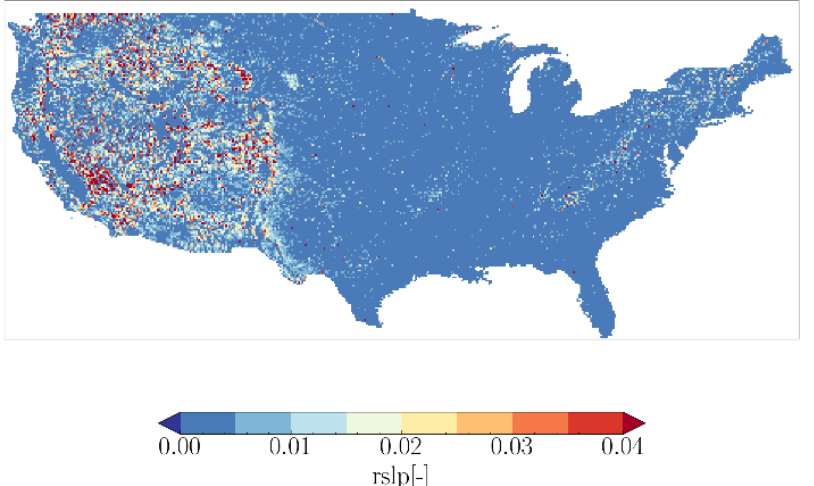

Figure 2: Important parameters over the study domain.

\section{Hydrology and Earth System Sciences \\ Discussions}

b) Bankfull width of main chamel
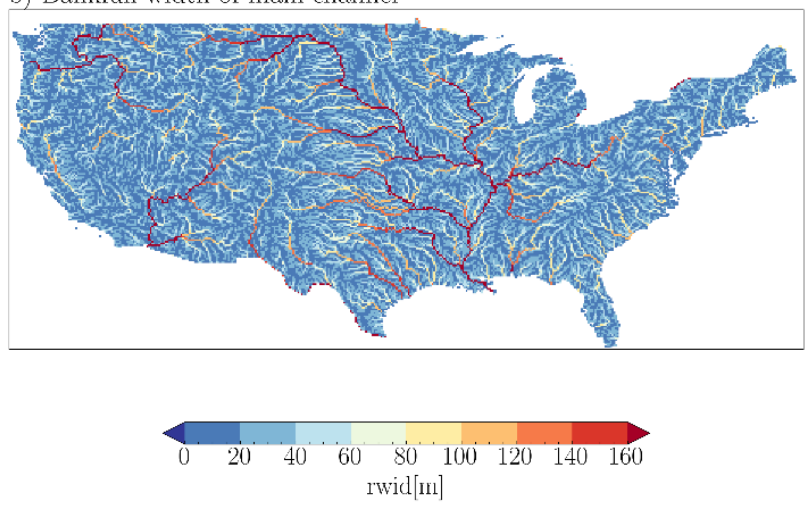

d) Manning roughness for main channel
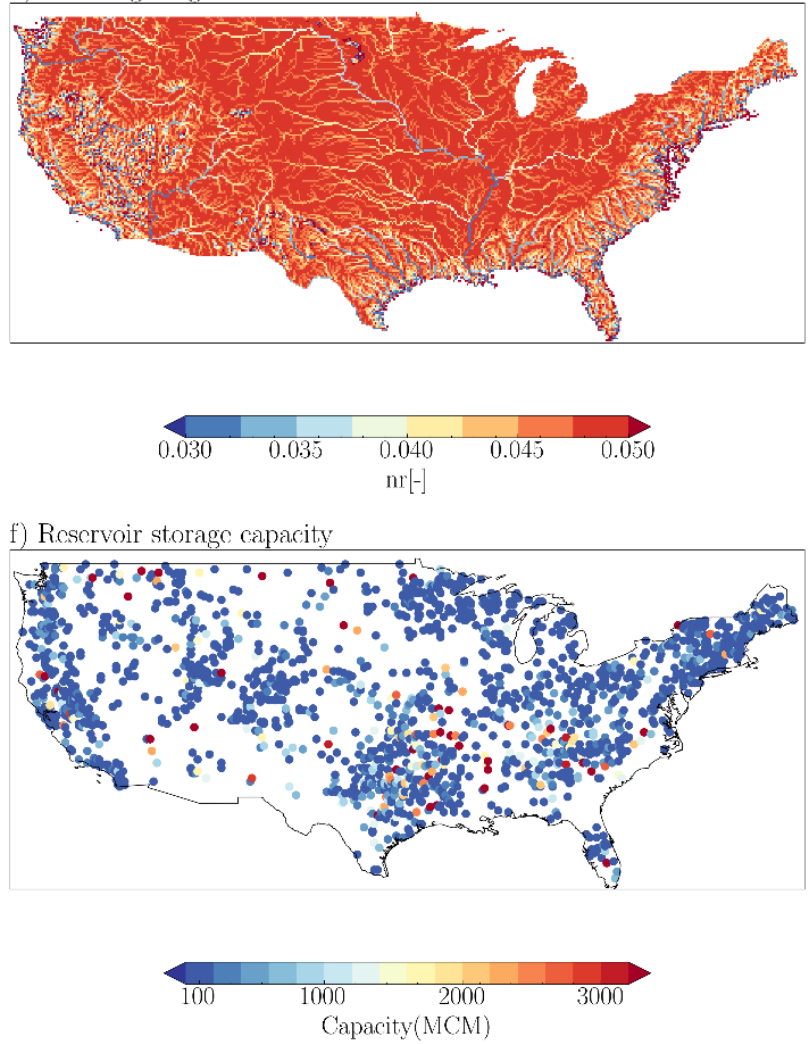
a. Accumulated upstream drainage area

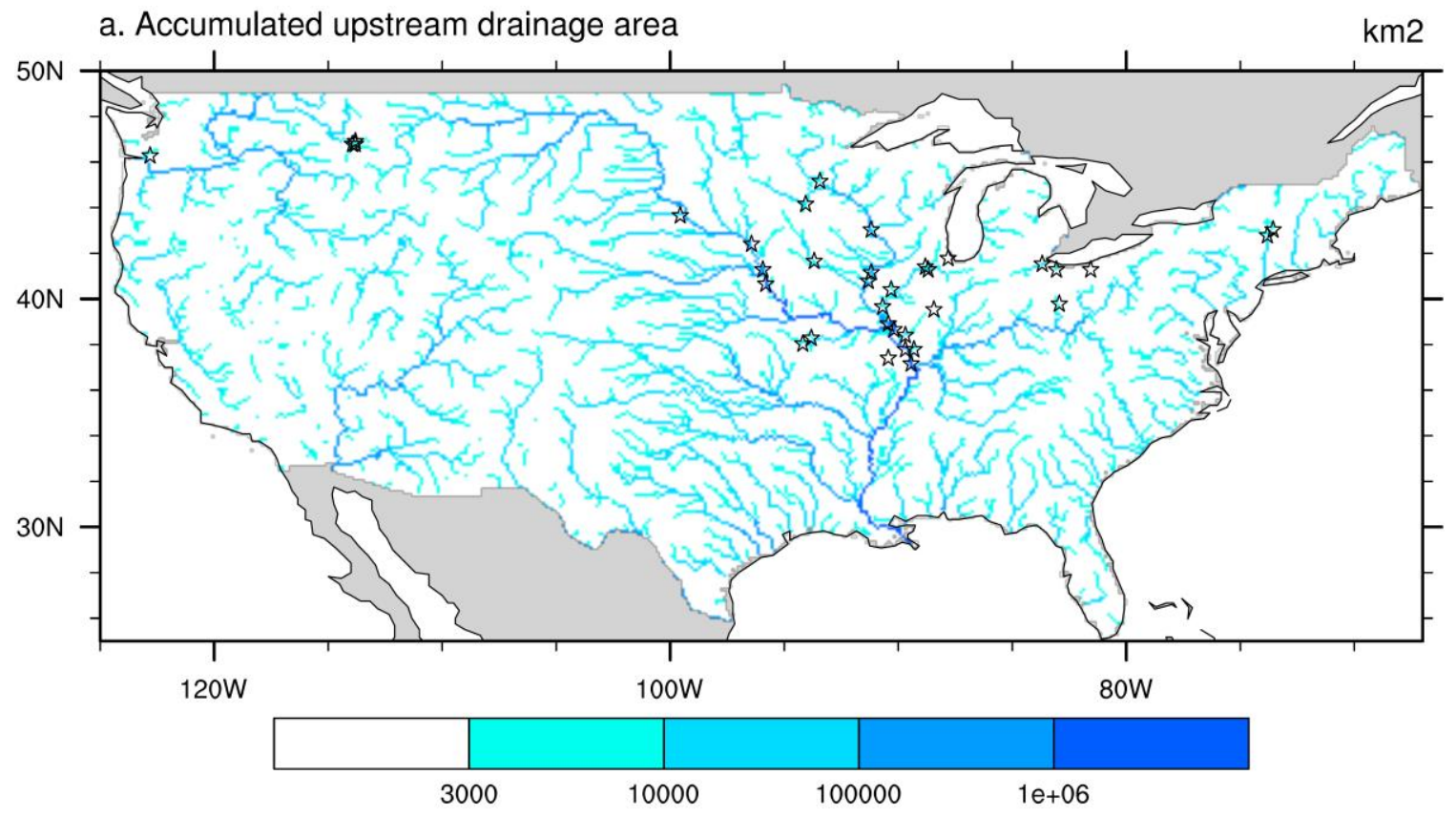

b. Change of local water residence time

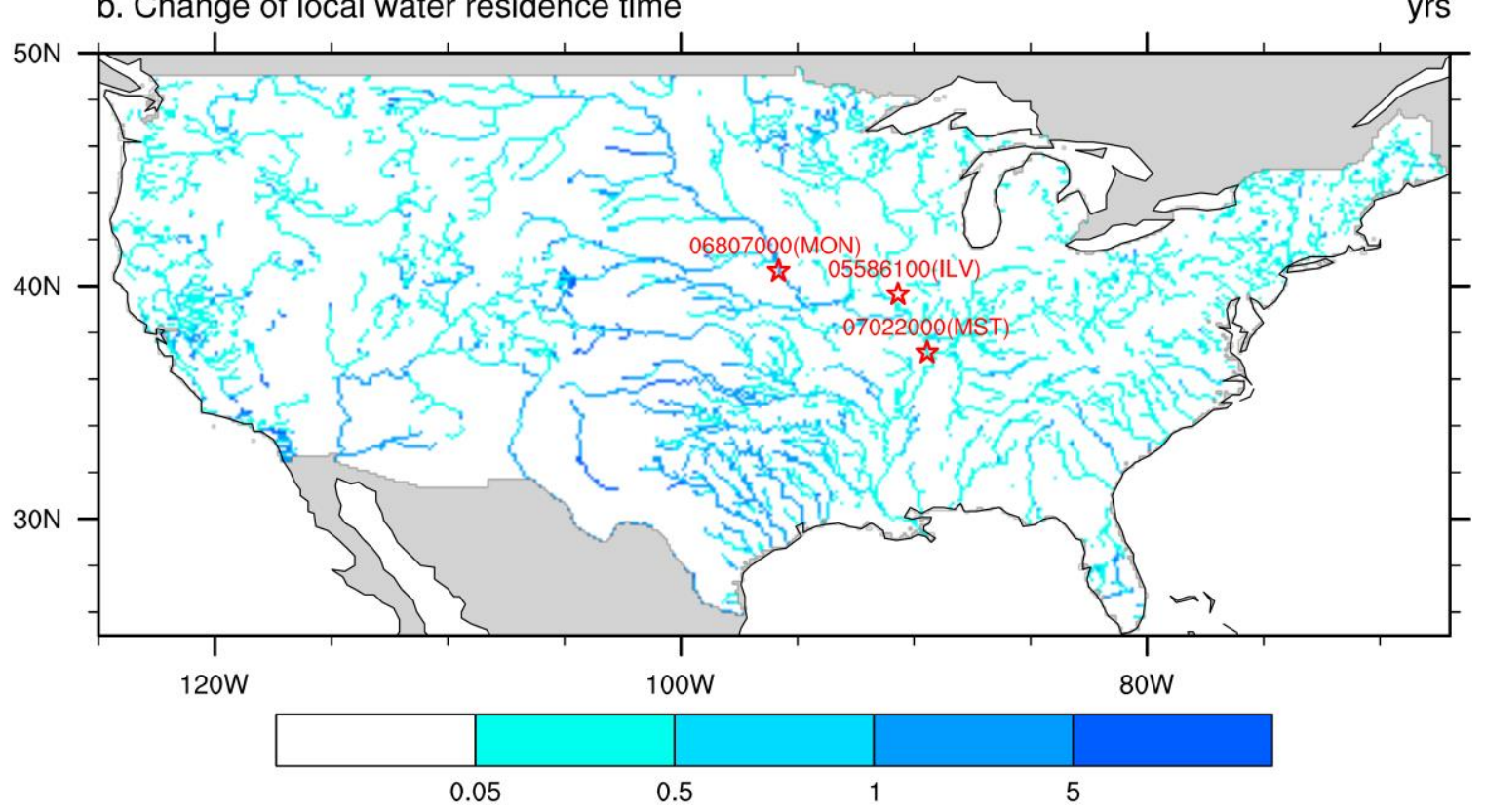

Figure 3: a. River network displayed using upstream drainage area and 35 selected USGS stations (black stars) along the river networks (approximated). b. change of channel water residence time due to upstream reservoirs and 3 representative stations (red stars). 
https://doi.org/10.5194/hess-2021-491

Preprint. Discussion started: 30 September 2021

(c) Author(s) 2021. CC BY 4.0 License.

(c) (i)
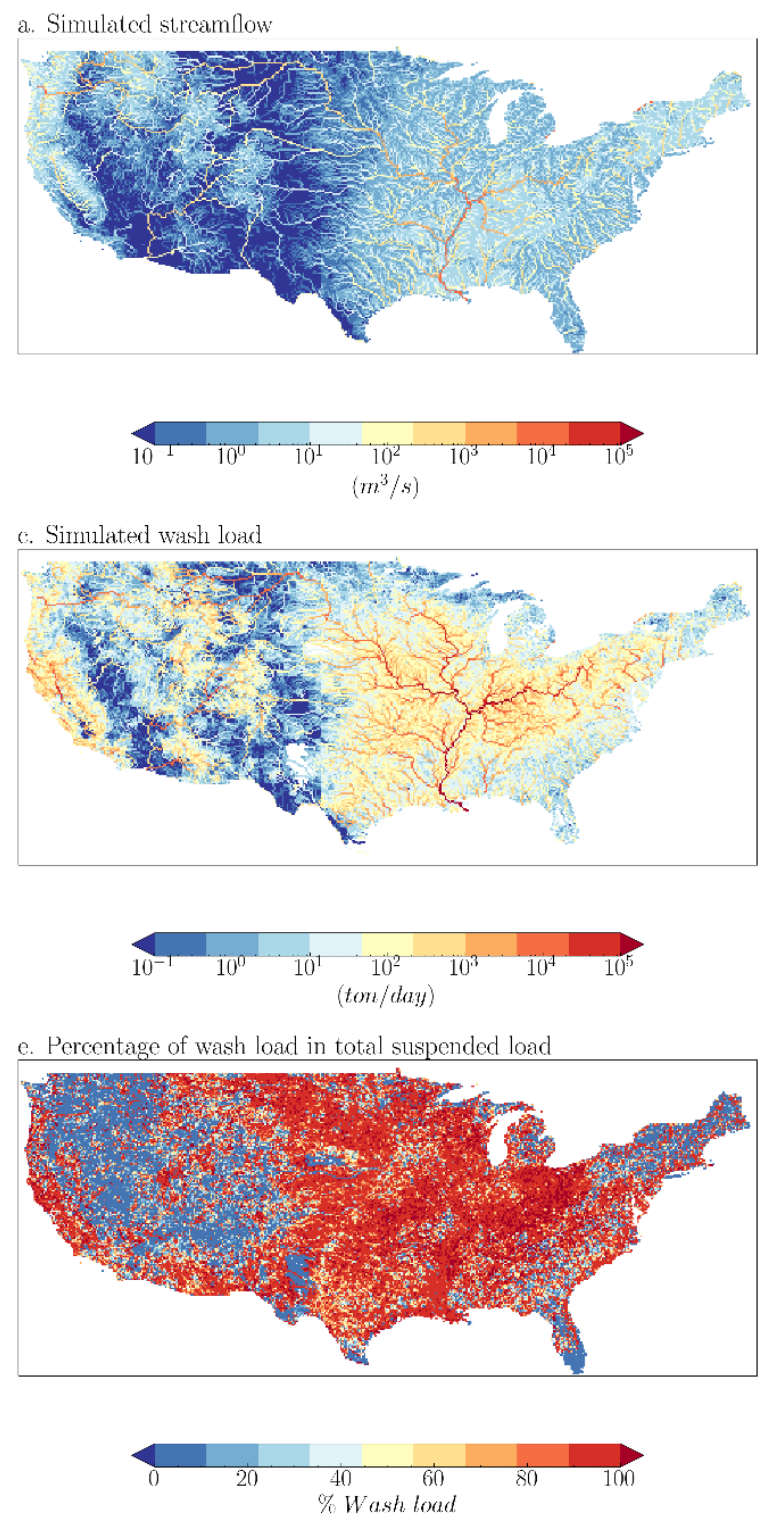

Figure 4: Spatial maps of simulated streamflow, total suspended load, wash load and suspended bed1055 material load averaged in 1990-2012.
Hydrology and
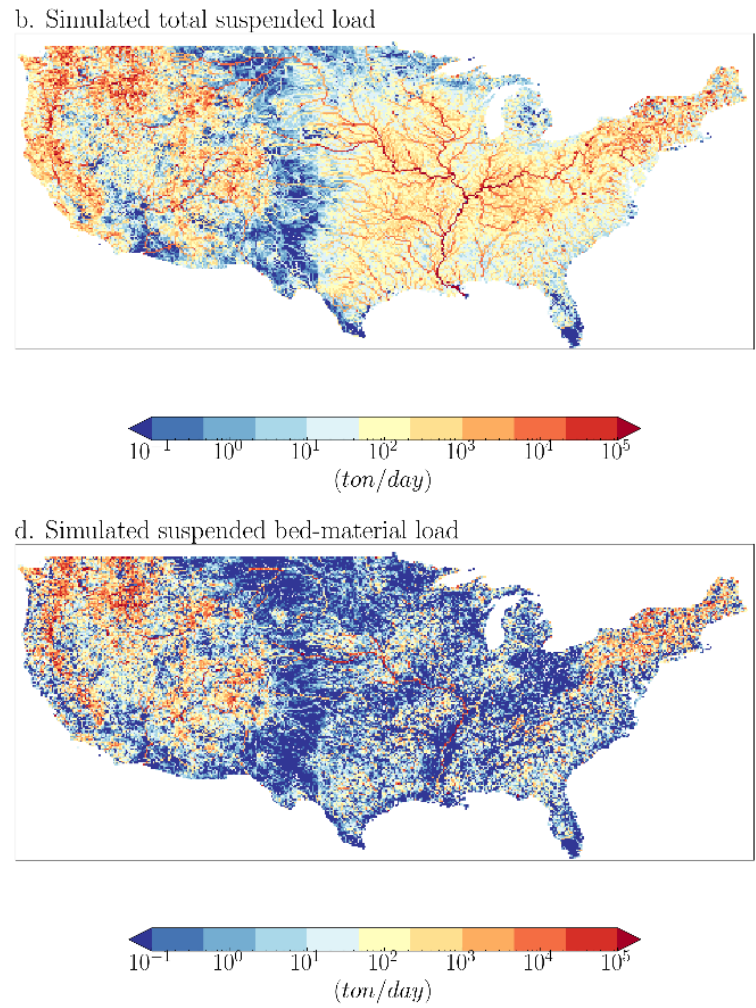
https://doi.org/10.5194/hess-2021-491
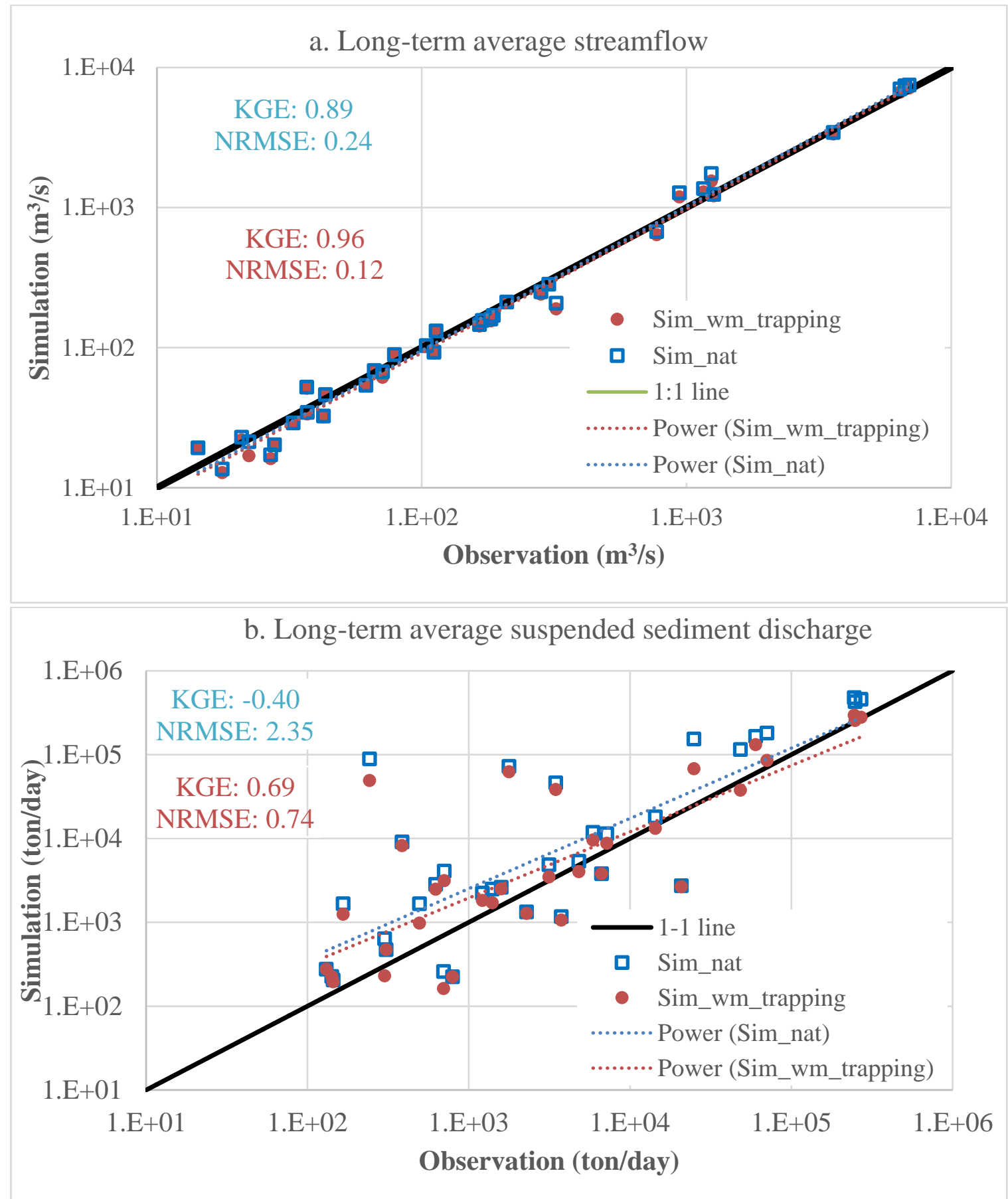

Figure 5: Simulated versus observed annual mean discharge of water and total suspended load in 1990-2012. Each dot represents one USGS station. 
a. KGE of monthly streamflow

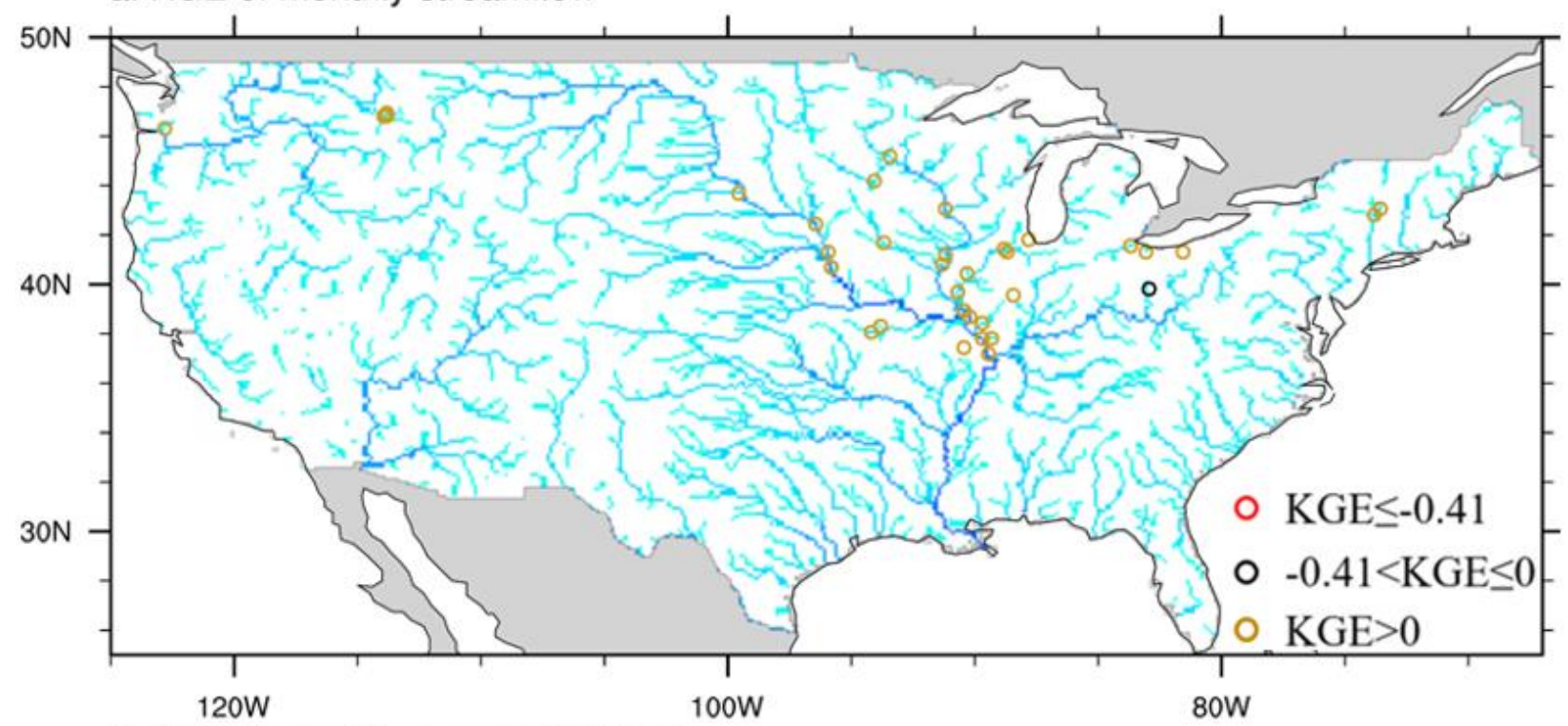

b. KGE of monthly suspended load

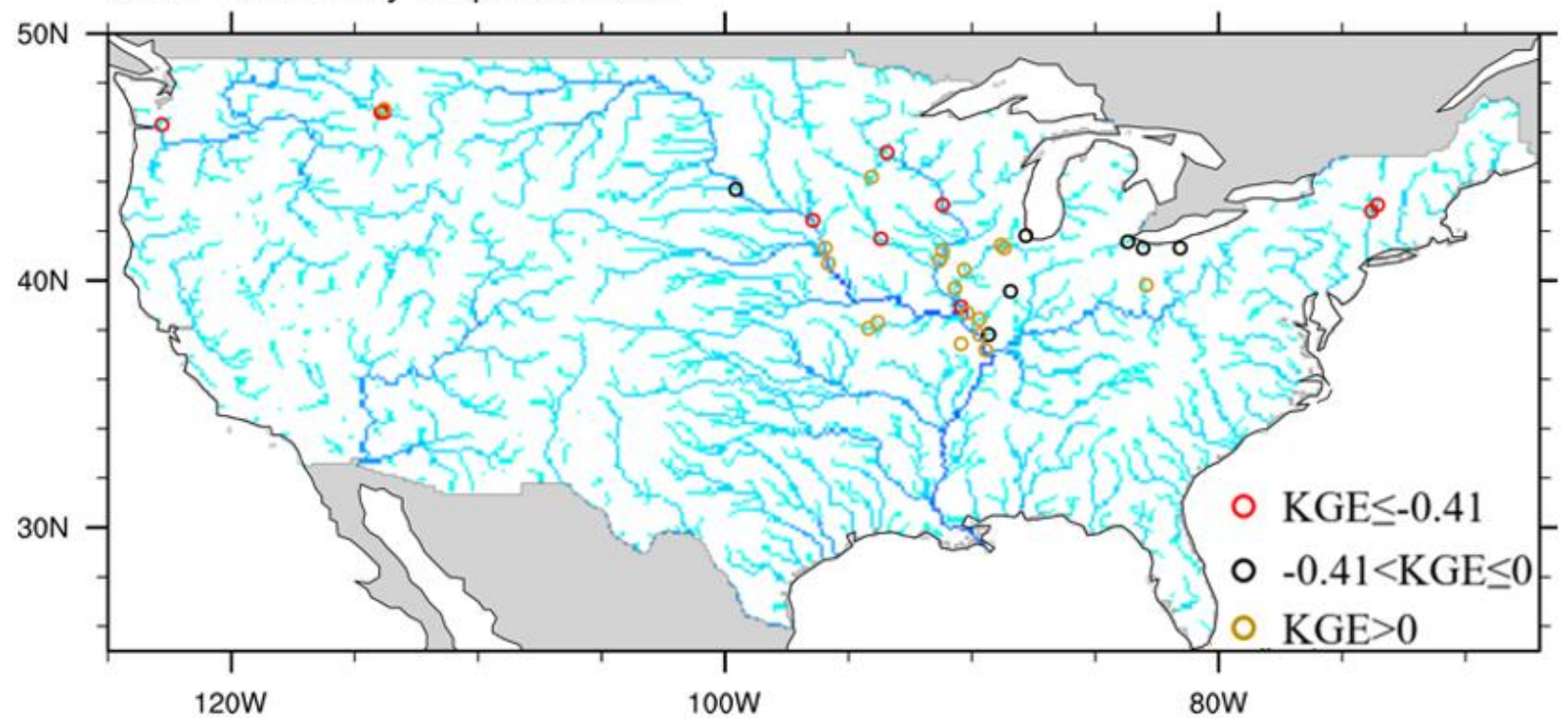

Figure 6: Evaluation of simulated monthly streamflow and suspended sediment at the selected USGS stations in each grid (in different tones of blue). 

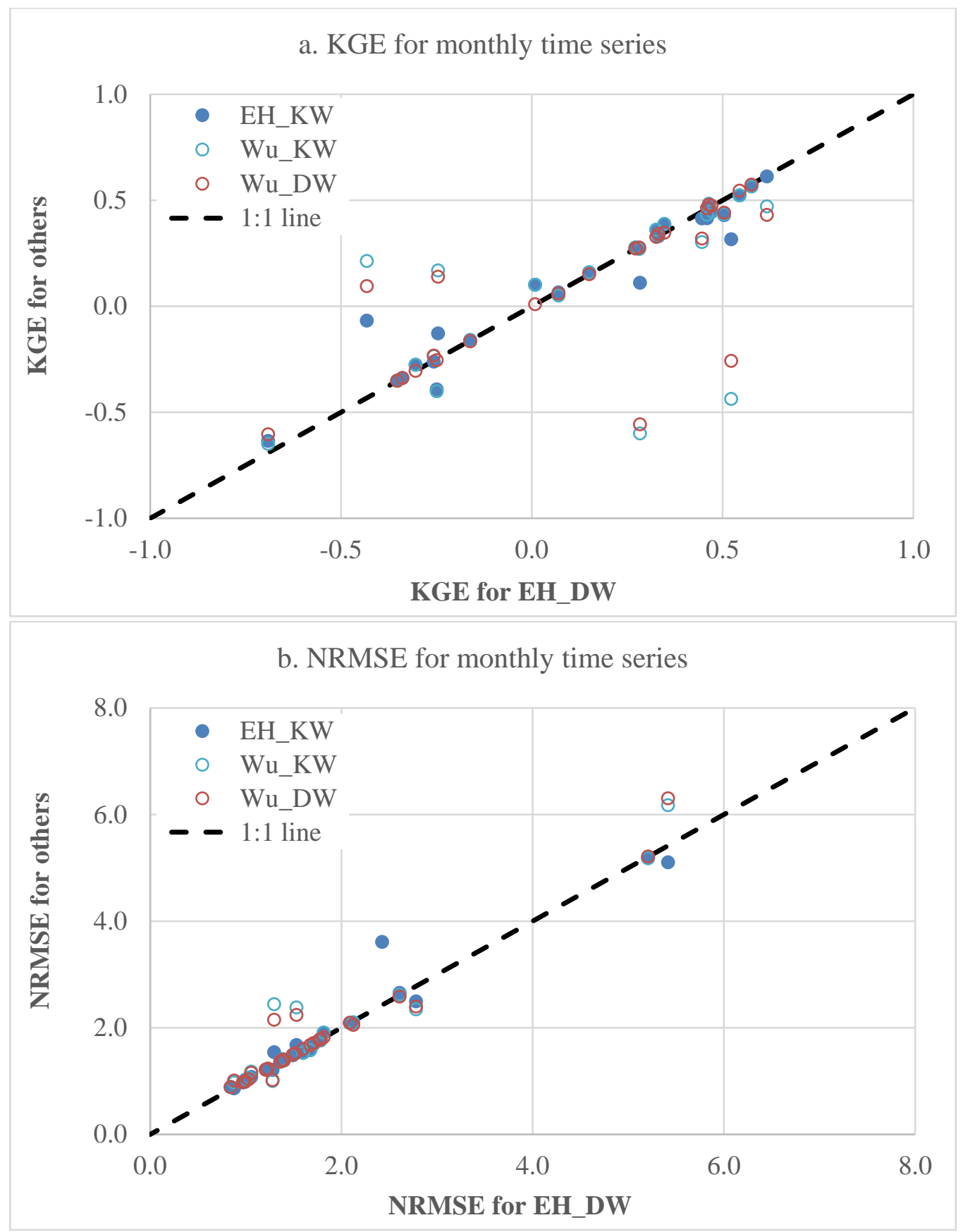

Figure 7: Comparison of model structure in terms of KGE and NRMSE between the simulated and observed monthly time series at different USGS gauges. EH and Wu stand for the Engelund-Hansen and Wu's formulas respectively. DW and KW stand for the diffusion and kinematic wave routing methods respectively. 
a. Simulated and observed monthly streamflow
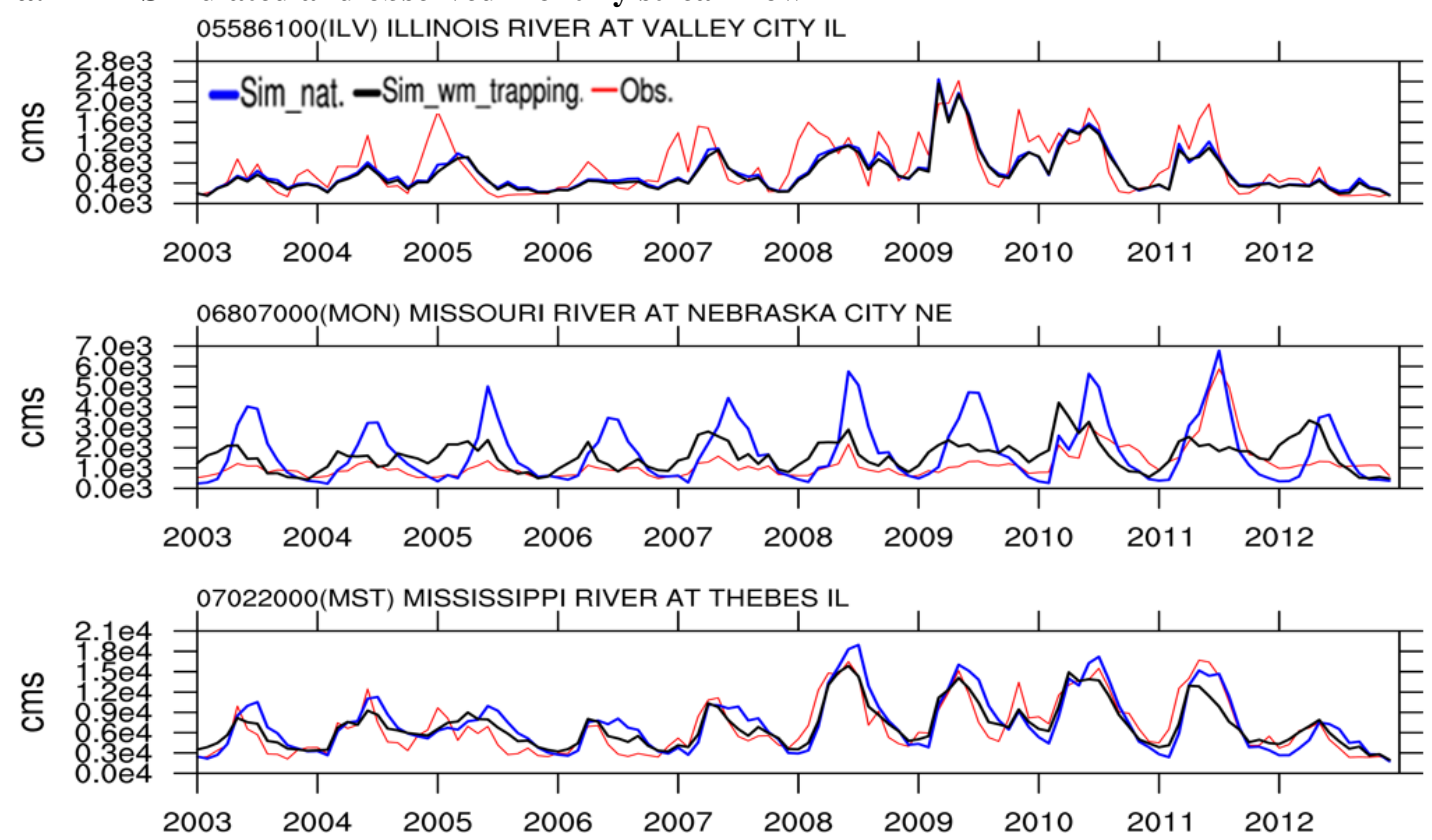

b. $\quad$ Simulated and observed monthly sediment discharge
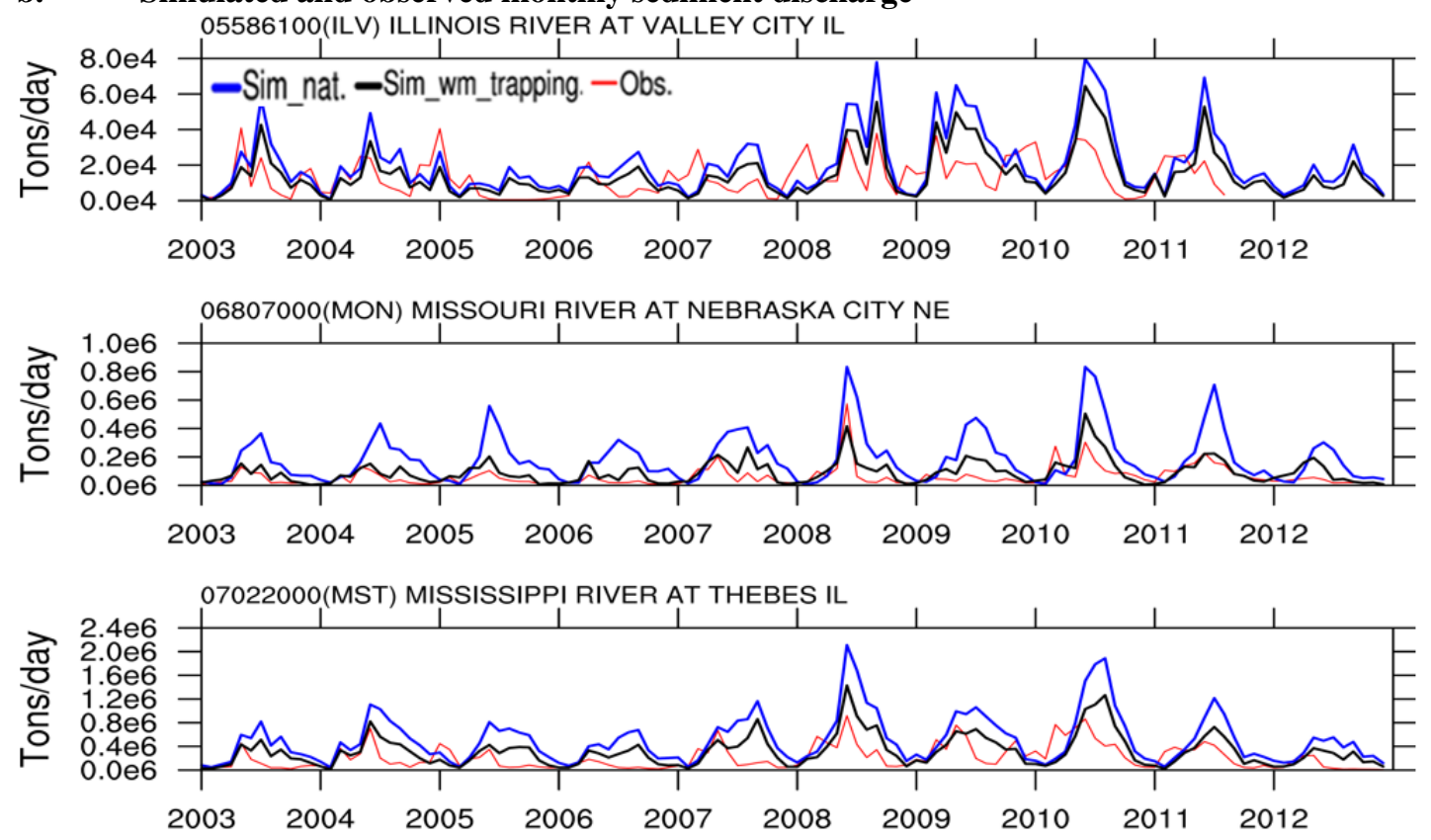

Figure 8: Simulated and observed monthly streamflow and suspended sediment discharge at three USGS gauges 1090 representative of different levels of flow regulation. For clarity, only the sim_nat and sim_wm_trapping results are displayed here. 
a. Change of KGE of streamflow after including reservoir effects

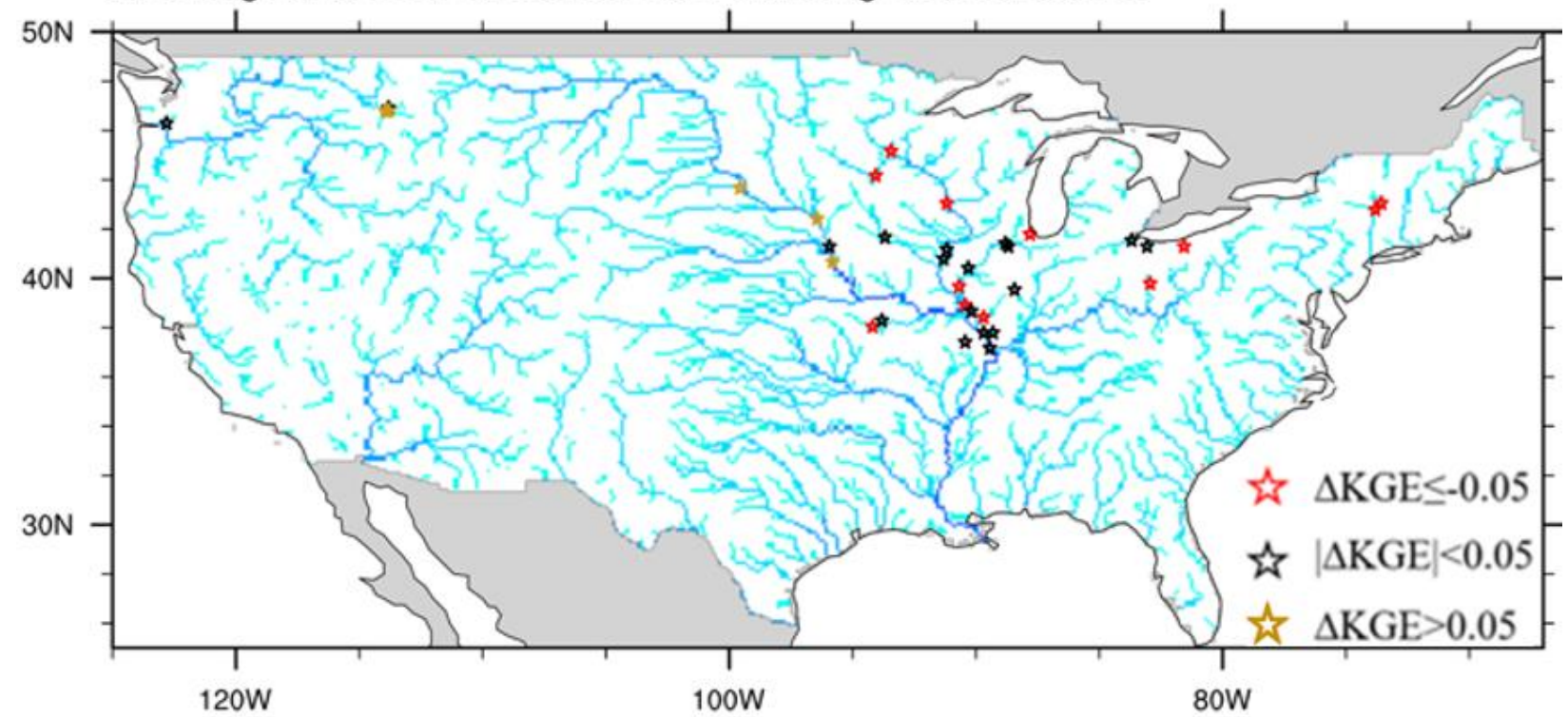

b. Change of KGE of suspended load after including reservoir effects

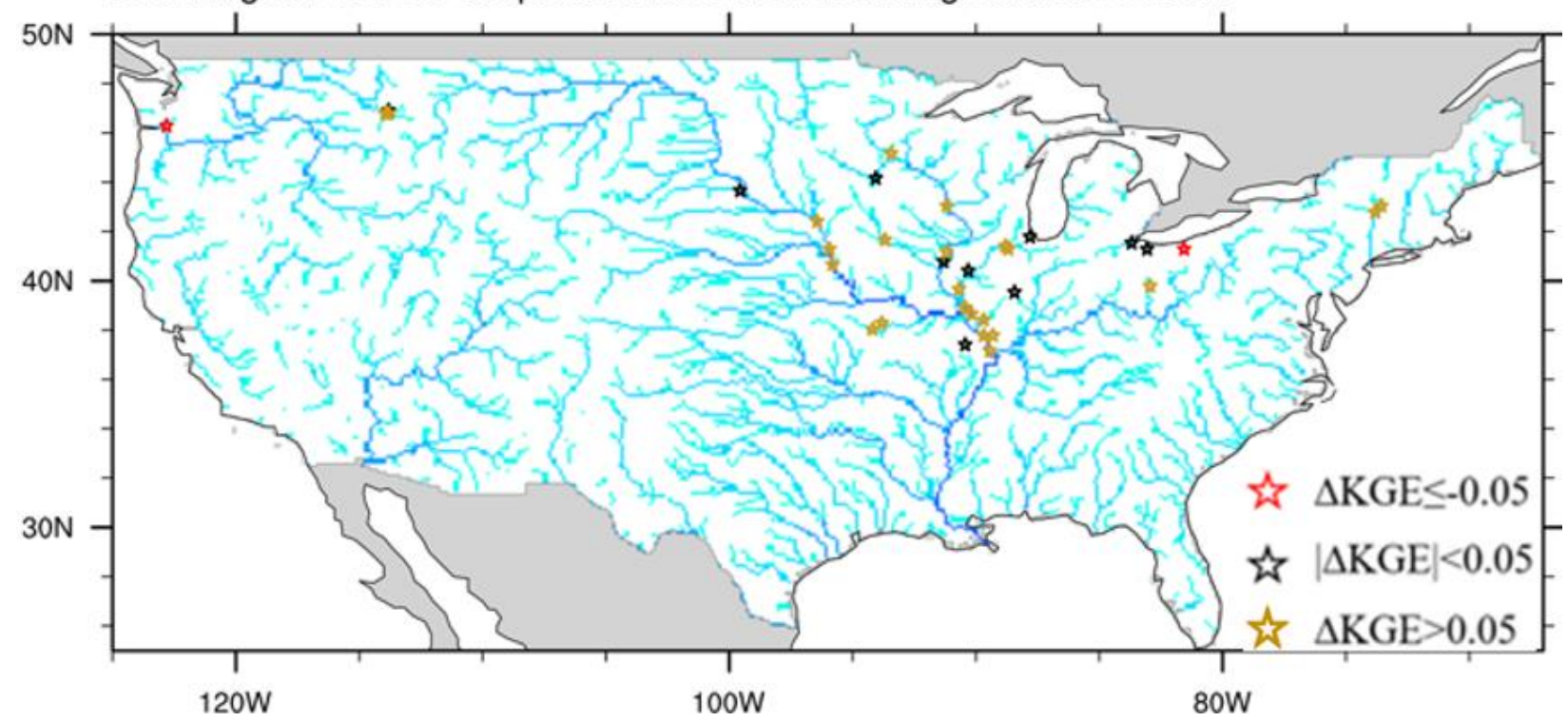

Figure 9: Change of KGE from sim_nat to sim_wm_trapping for monthly streamflow and suspended sediment at the upstream drainage areas at each grid (in different tones of blue). 
https://doi.org/10.5194/hess-2021-491

Preprint. Discussion started: 30 September 2021

(c) Author(s) 2021. CC BY 4.0 License.
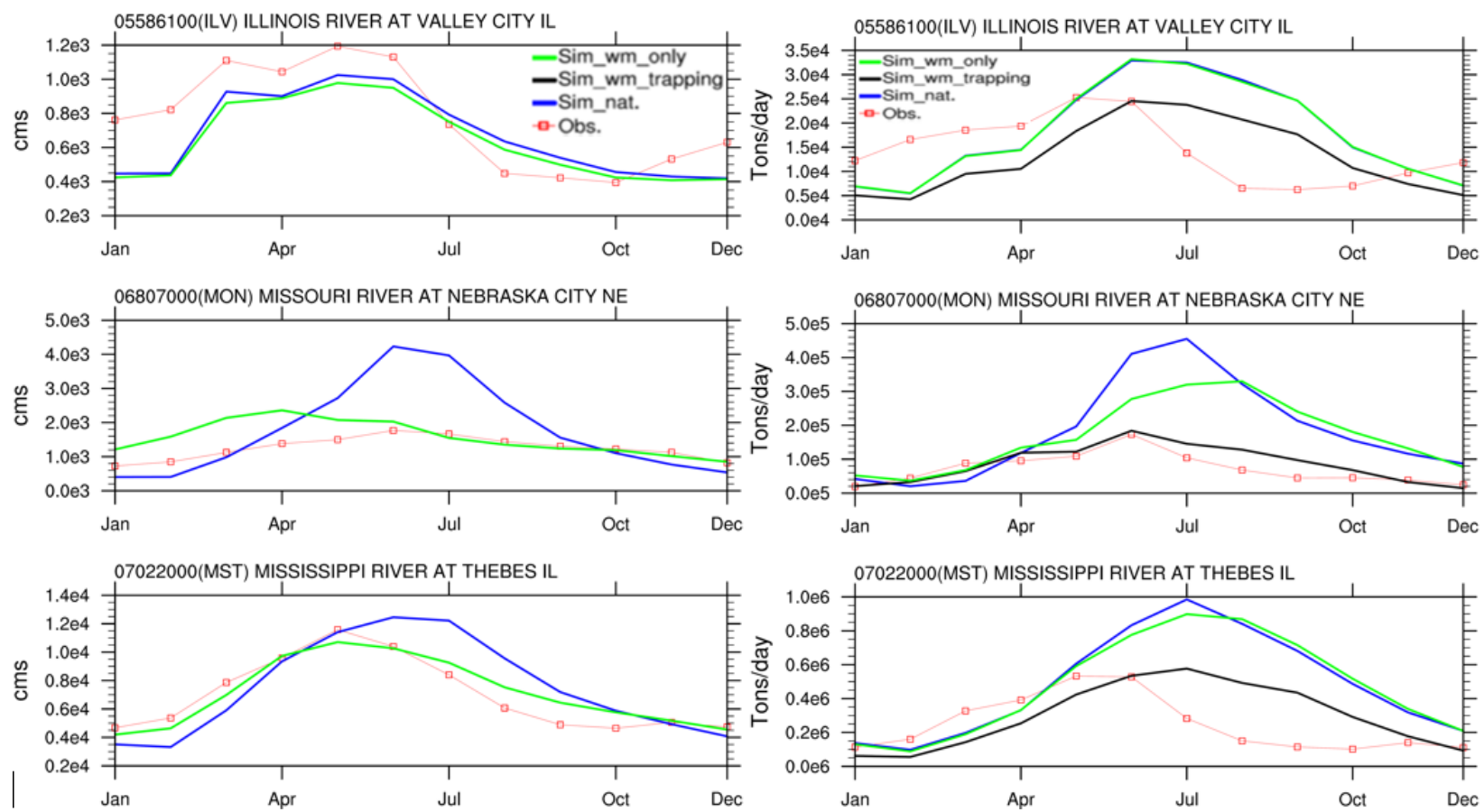

Figure 10: Simulated and observed mean monthly streamflow (left) and suspended sediment discharge (right) at three USGS gauges representative of different levels of flow regulation. 
a. Per. diff. in suspended load due to $+10 \%$ d50

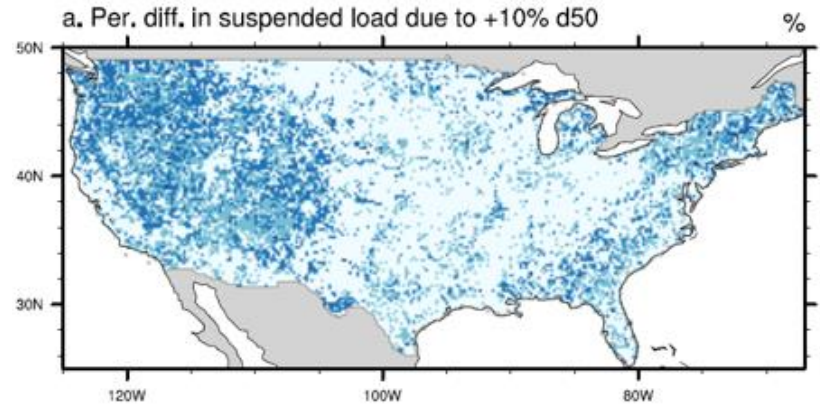

b. Per. diff. in suspended load due to $-10 \%$ d50
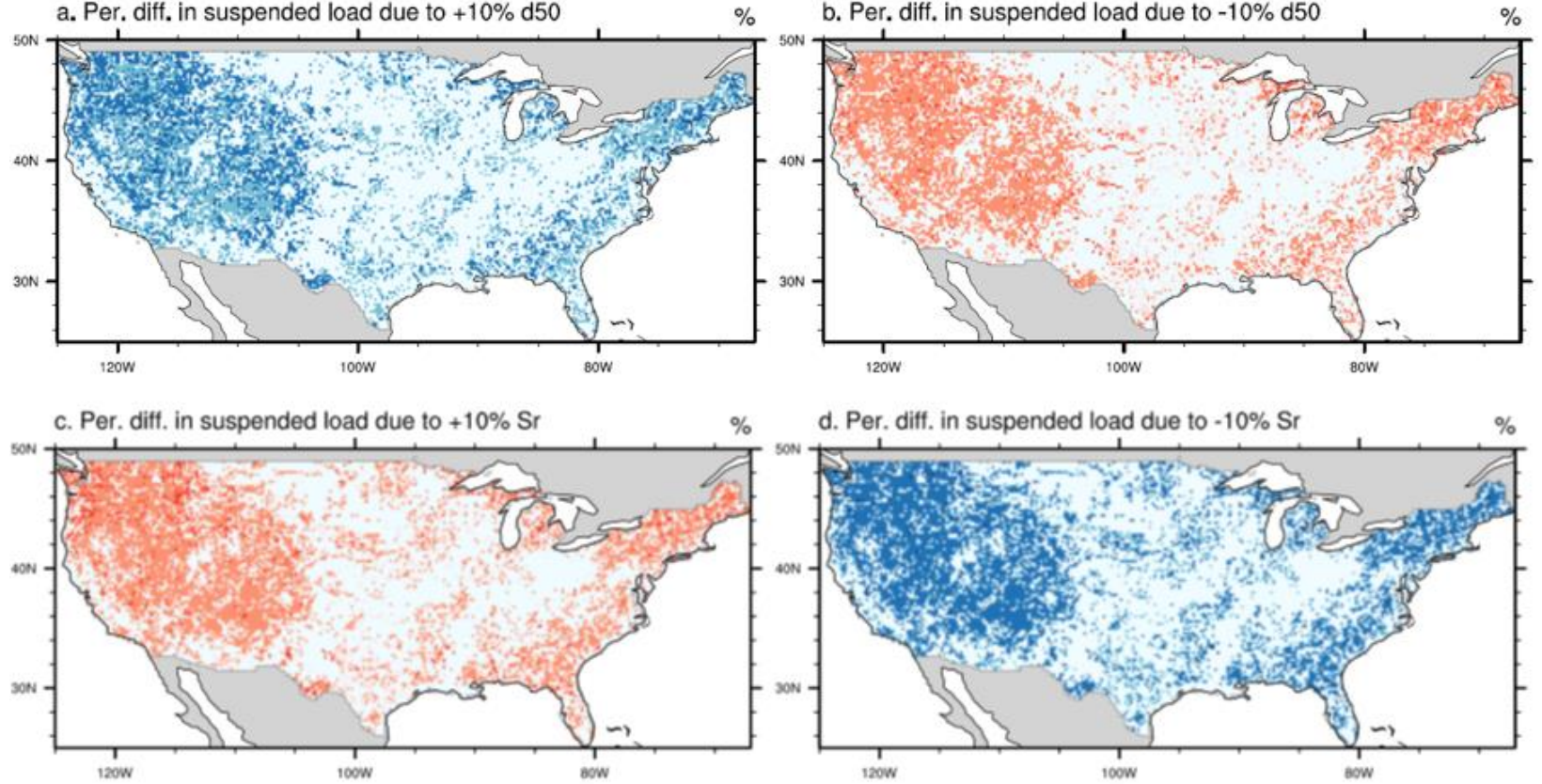

d. Per. diff. in suspended load due to $-10 \% \mathrm{Sr}$

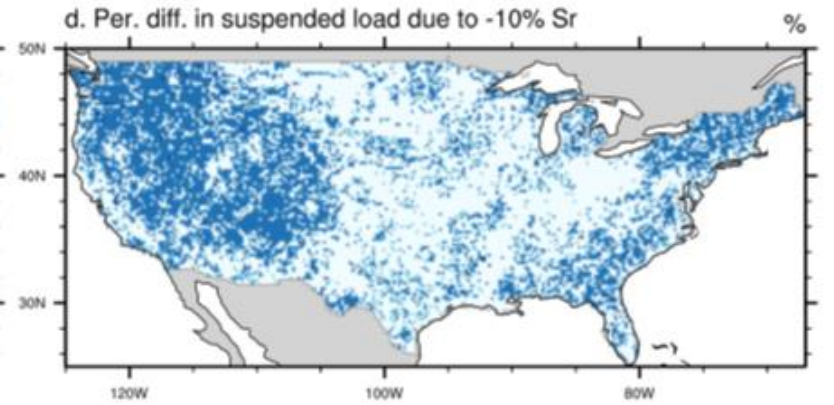

e. Per. diff. in suspended load due to $+10 \% \mathrm{nr}$
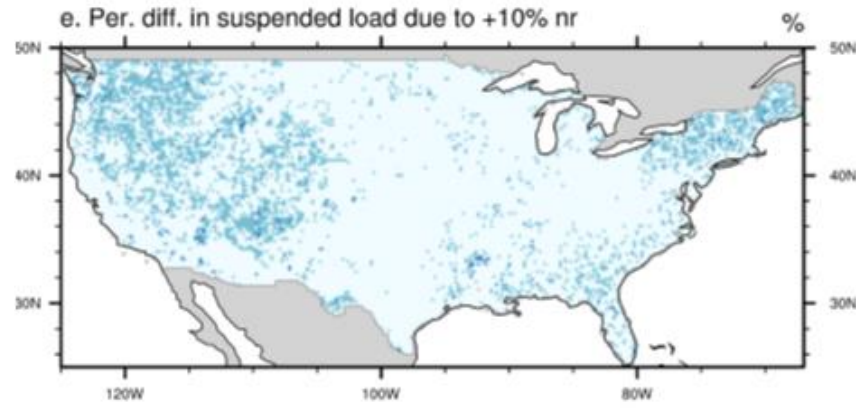

f. Per. diff. in suspended load due to $-10 \% \mathrm{nr}$
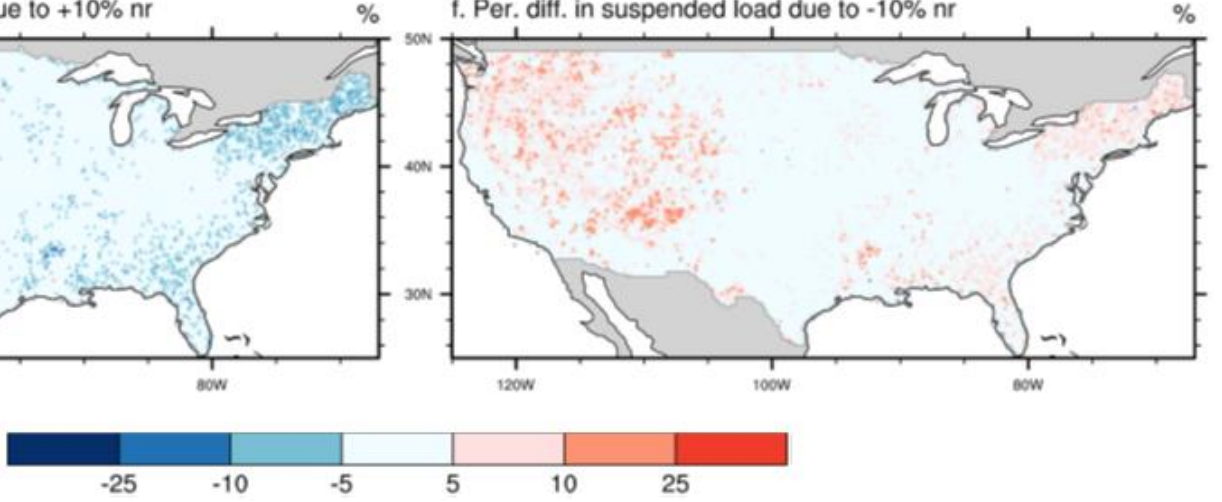

1120 Figure 11: Spatial patterns of sensitivity of median bed-material size (d50) (a, b), channel slope (rslp) (c, d), and Manning's roughness for channels $(n r)(e, f)$. At each grid, the percentage change of suspended load is calculated as $100 \% *\left(S_{1}-S_{0}\right) / S_{0}$, where $S_{1}$ and $S_{0}$ are the average suspended load 1990-2012 simulated with the parameter changing by $10 \%$, and the average suspended load simulated with the original parameters, respectively. 
https://doi.org/10.5194/hess-2021-491

Preprint. Discussion started: 30 September 2021

(c) Author(s) 2021. CC BY 4.0 License.

(c) (i)

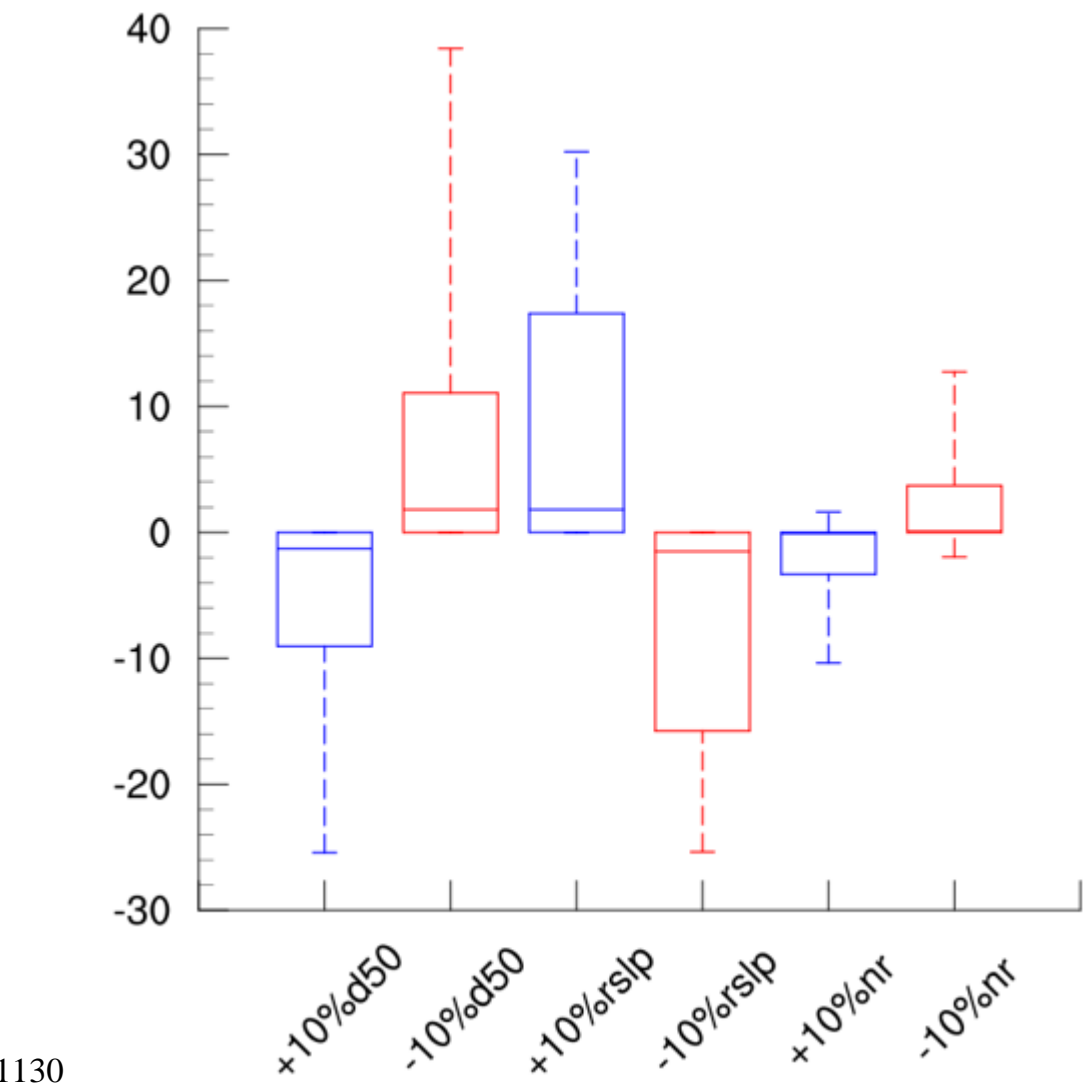

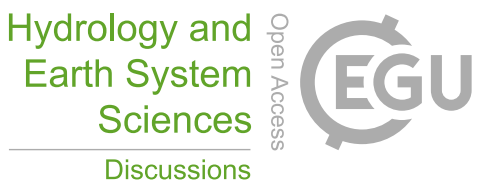

Figure 12: Boxplot of the changes in total suspended load when changing the parameters. 
a. Impacts of water management on streamflow to the coasts

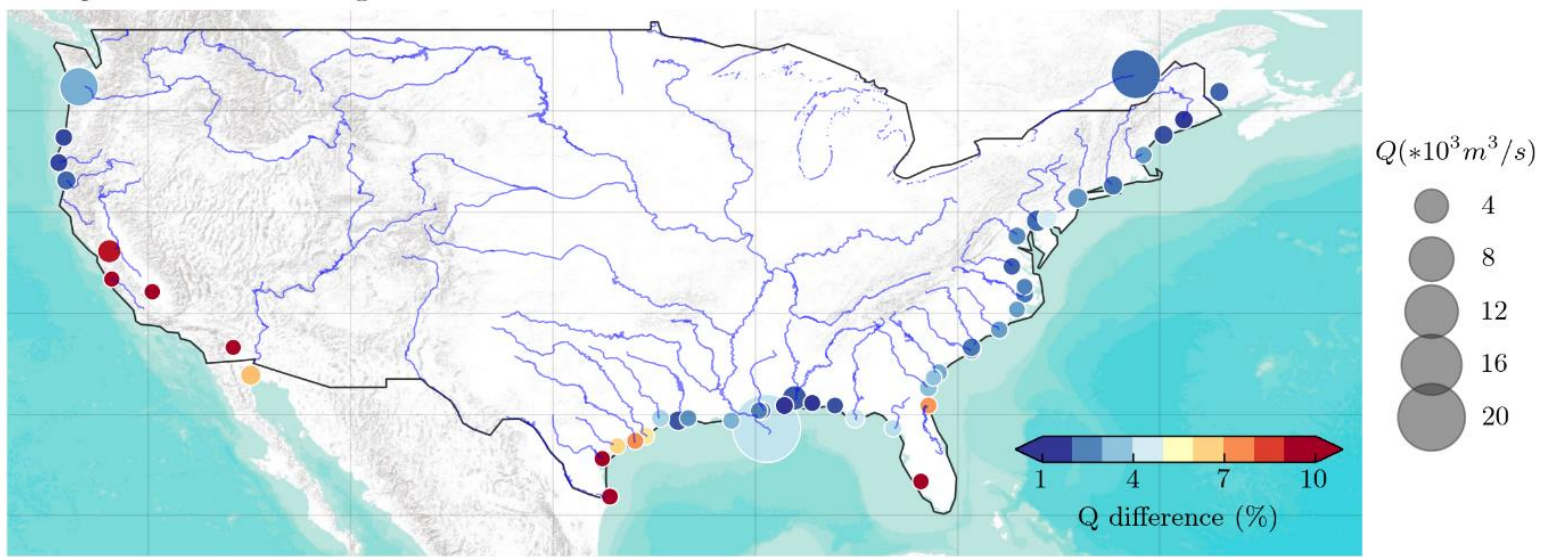

b. Impacts of reservoirs on wash load to the coasts

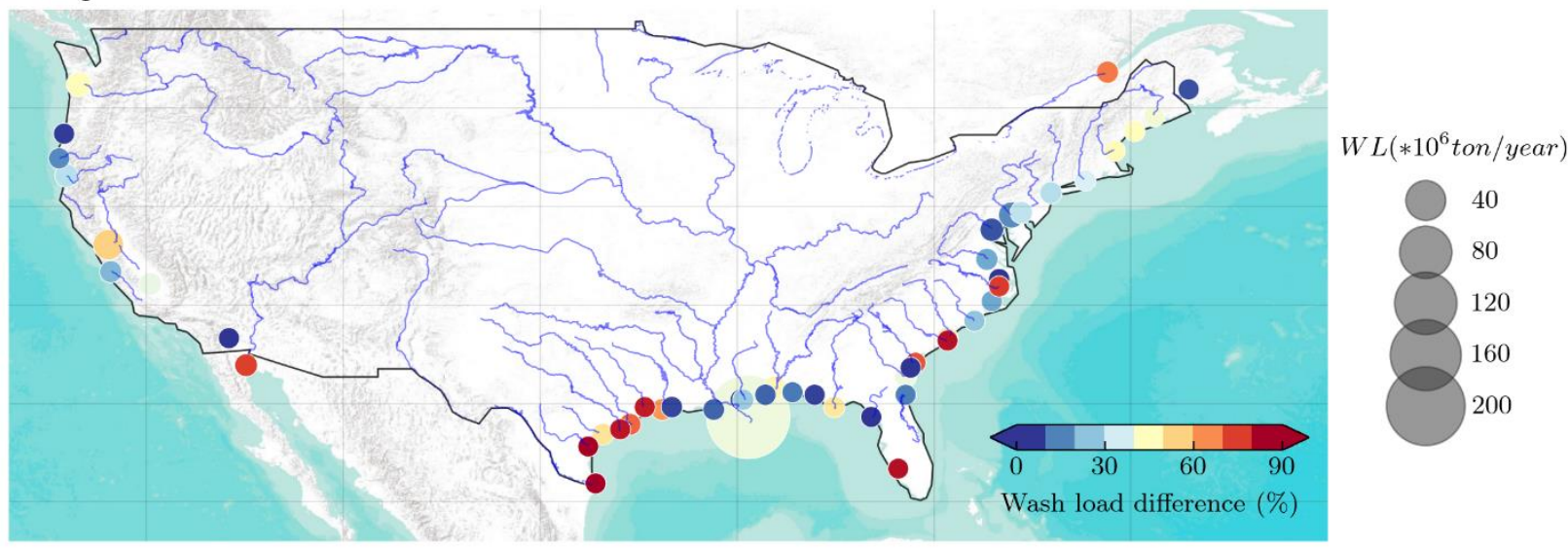

Figure 13: Impacts of reservoirs on (a) streamflow and (b) wash load to the coasts. Each dot in Figure 13 represents the lat/lon grid at the river mouth of a river system. The larger the dot size, the larger the freshwater or suspended sediment discharge simulated with Sim_wm_trapping. The color of each dot represents the percentage of freshwater or suspended sediment discharge that is reduced by water management or reservoirs, i.e., (sim_nat -

Sim_wm_trapping)/sim_nat. 